\title{
More Than Meets the Eye in Bacterial Cellulose: Biosynthesis, Bioprocessing, and Applications in Advanced Fiber Composites ${ }^{\mathrm{a}}$
}

\author{
Koon-Yang Lee, Gizem Buldum, Athanasios Mantalaris, \\ Alexander Bismarck*
}

Bacterial cellulose $(\mathrm{BC})$ nanofibers are one of the stiffest organic materials produced by nature. It consists of pure cellulose without the impurities that are commonly found in plant-based cellulose. This review discusses the metabolic pathways of cellulose-producing bacteria and the genetic pathways of Acetobacter xylinum. The fermentative production of $\mathrm{BC}$ and the bioprocess parameters for the cultivation of bacteria are also discussed. The influence of the composition of the culture medium, $\mathrm{pH}$, temperature, and oxygen content on the morphology and yield of $\mathrm{BC}$ are reviewed. In addition, the progress made to date on the genetic modification of bacteria to increase the yield of $\mathrm{BC}$ and the large-scale production of $\mathrm{BC}$ using various bioreactors, namely static and agitated cultures, stirred tank, airlift, aerosol, rotary, and membrane reactors, is reviewed. The challenges in commercial scale production of $\mathrm{BC}$ are thoroughly discussed and the efficiency of various bioreactors is compared. In terms of the application of BC, particular emphasis is placed on the utilization of $\mathrm{BC}$ in advanced fiber composites to manufacture the next generation truly green, sustainable and renewable hierarchical composites.
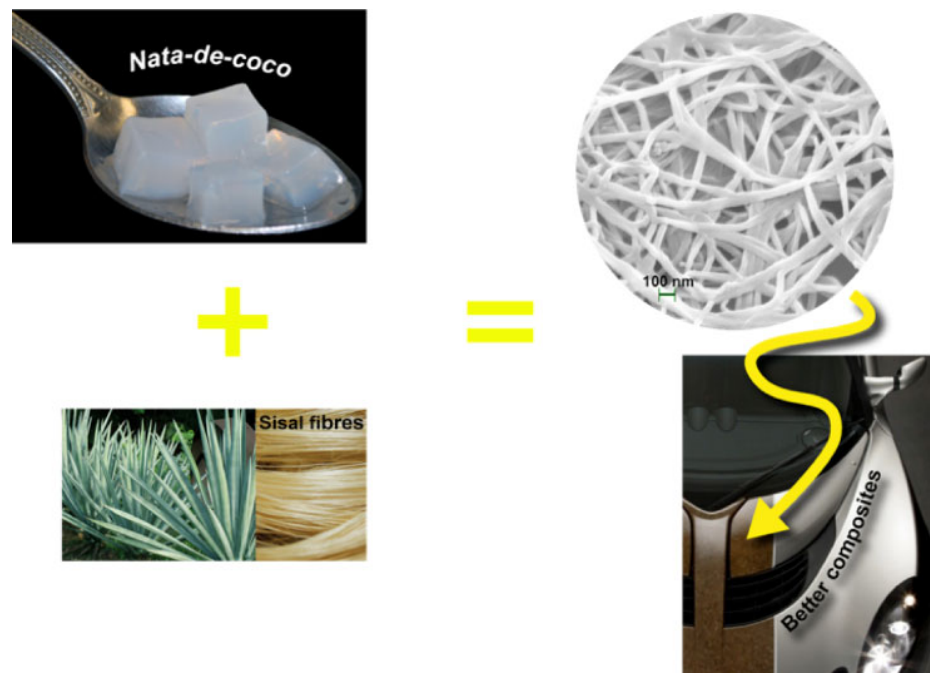

\section{Introduction}

Bacterial cellulose (BC) was first described by Brown ${ }^{[1]}$ after he discovered an organism in the Mycoderma aceti ("mother

K.-Y. Lee, A. Bismarck

Polymer and Composite Engineering (PaCE) Group, Faculty of Chemistry, Institute of Materials Chemistry and Research, University of Vienna, Währinger Straße 42 A-109o Vienna, Austria E-mail: alexander.bismarck@univie.ac.at1, a.bismarck@imperial. ac.uk

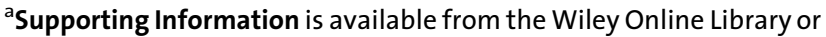
from the author.

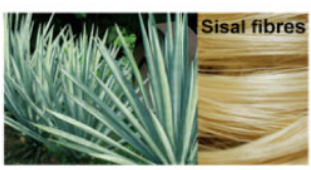

of vinegar") which produced, when cultivated in a medium containing fructose, extremely strong membranes. He suggested for this organism the name A. xylinum. In his

K.-Y. Lee, G. Buldum, A. Bismarck

Polymer and Composite Engineering (PaCE) Group, Department of Chemical Engineering, Imperial College London, South Kensington Campus, SW7 $2 \mathrm{AZ}$ London, UK

G. Buldum, A. Mantalaris

Biological System Engineering Laboratory, Department of Chemical Engineering, Imperial College London, South Kensington Campus, SW7 2AZ London, UK 
original paper, Brown describes his observations as: "A pure cultivation of the "vinegar plant" when commencing to grow in a liquid favorable to its free development, is usually first noticed as a jelly-like translucent mass on the surface of the culture fluid; this growth rapidly increases until the whole surface of the liquid is covered with a gelatinous membrane, which, under very favorable circumstances, may attain a thickness of $25 \mathrm{~mm}$."The gelatinous membrane that he observed during the cultivation was shown to be chemically identical to cotton cellulose by Barsha and Hibbert $^{[2]}$ through a series of experiments involving methylation, acetylation, acetolysis, and hydrolysis. This cellulose is now known as bacterial or microbial cellulose. Brown $^{[1]}$ also found that this gelatinous membrane was very tough, especially if one attempts to tear across the plane of growth. However, it is still an open question as to why bacteria produce cellulose. A few plausible hypotheses have been put forward: i) to maintain close proximity to the surface of the culture medium where the oxygen concentration is highest, ${ }^{[3]}$ ii) to protect against ultraviolet light, ${ }^{[4]}$ and iii) to protect against heavy metal ions and improve nutrient transport by diffusion. ${ }^{[5]}$

Bacterial cellulose membranes were described by Sisson ${ }^{[6]}$ as being "tough dense parchments, very resistant to the penetration of liquids." So it comes as no surprise that it is the mechanical properties of BC, which attracted significant attention and numerous efforts have been poured into the research and development of BC for various applications. These include biomedical applications, ${ }^{[7,8]}$ the production of high quality papers, ${ }^{[5]}$ diaphragms for electroacoustic transducers, ${ }^{[9]}$ optically transparent films, ${ }^{[10,11]}$ stabilizers for emulsions ${ }^{[12-15]}$ and foams, ${ }^{[16]}$ and reinforcement for fine structures, such as fibers, polymer foams, and the matrices of composites. ${ }^{[17-19]}$ The size of BC nanofibers, coupled with its high water holding capacity, renders BC suitable for wound dressings, allowing the transfer of medicine into the wound while serving as an efficient physical barrier against external infection. ${ }^{[20]} \mathrm{BC}$ networks can also be used as medical pads ${ }^{[21]}$ and artificial skin. ${ }^{[9]}$ The concept of utilizing $\mathrm{BC}$ as a biocompatible self-constructing protective packaging won the third prize in the Bayer Materials Science VisionWorks Award in 2007. The extensive use of BC in these applications is due to the fact that $\mathrm{BC}$ consists of pure cellulose without impurities after mild refinement of the produced BC gel using hot aqueous $\mathrm{NaOH}$. Non-cellulosic materials, such as hemicellulose, lignin, pectin, and wax are commonly associated with plant-based (nano)cellulose but not present in $B C,{ }^{[5]}$ cotton being the exception. ${ }^{[22]}$ We have also included a list of links to some videos on the biosynthesis of $B C$ and application of $\mathrm{BC}$ in wound dressing and fashion in the Supporting Information.

Bacterial cellulose is predominantly left-hand twisted, ${ }^{[23]}$ produced as nanofibers naturally with individual fibers ranging from 25 to $100 \mathrm{~nm}$ in diameter and several micrometers in length. ${ }^{[5,24]}$ Moreover, the randomly aligned BC nanofibers in as produced BC membranes can be easily orientated uniaxially or uniplanar if a stress is applied to the membrane during drying. ${ }^{[6]}$ When still wet, as produced $\mathrm{BC}$ pellicles can easily be disintegrated into loose nanofibrils. This makes BC different from plantderived micro- or nanofibrillated cellulose, which has to be produced by homogenization or fibrillation of cellulosic plant biomass to obtain cellulose with nanometer dimensions. ${ }^{[25-27]}$ It is also worth mentioning that while $B C$ is the "gold standard" for nanocellulose as it is produced in the nanometer-scale in a controlled manner by bacteria, the earliest report on the preparation of what is now called micro- or nanofibrillated cellulose by ultrasonication of natural fiber microfibrils, namely ramie, hemp, and cotton, we could find stems from 1946 by Wuhrmann et al. ${ }^{[28]}$ They found that by treating natural fibers in strong ultrasound for 3-10 min allowed for the disintegration of the fibers into what they called elementary fibrils while the fiber texture was retained (Figure 1, top). The smallest fibrils had a diameter of $6-7 \mathrm{~nm}$ as determined by SEM (Figure 1, bottom). These finest fibrils were called elementary fibrils because their size was independent of whether they were produced from natural fibers, bacterial cellulose, tunicate cellulose, or rayon. ${ }^{[29]}$ Because of the discrepancy between the dimensions of elementary fibrils determined by SEM or $\mathrm{X}$-ray diffraction it was noted that these fibrils must contain a relatively large fraction of amorphous cellulose (around $36 \%$, which did also helped to explain the extraordinary flexibility of this fibrils. It was also noted that the differences between cellulose microfibrils produced by the ultrasonication from Valonia cellulose, BC, and cotton must be due to the differences in the degree of crystallinity and crystal width, affecting the packing of "otherwise perfect elementary fibrils forming the microfibril assemblies."[30]

Current major producers of BC include Xylos Corp., $\mathrm{USA}^{[31]}$ for wound dressing applications and Forschungszentrum für Medizintechnik und Biotechnologie (fzmb), $\mathrm{GmbH}$, Germany. Sony Japan together with Ajinomoto (Japan) developed acoustic diaphragms using $\mathrm{BC}^{[32]} \mathrm{BC}$, however, is mainly produced in the Philippines as a food product known as Nata-de-coco. ${ }^{[33]}$ fzmb sells wet BC which contains 94 wt\% of water. ${ }^{[34]}$ Even though BC is produced at relatively large scale, it is still rather expensive. For many of our studies, BC extracted from Nata de coco (CHAOKOH, Thailand) was used. A jar containing $500 \mathrm{~g}$ of Nata de coco gel yielded $\approx 1.5 \mathrm{~g}$ dry BC. This corresponded to a cost of È1 (EUR 1.18) per g of dry BC. Therefore, it is important to develop novel methods to optimize the production of $B C$ to reduce its cost. Successful commercialization of $B C$ will also depend on the applications where its relatively high cost can be justified by materials performance. This paper reviews the progress made to date in the biosynthesis and bioprocessing of $\mathrm{BC}$, and its potential application in

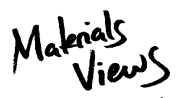

www.MaterialsViews.com

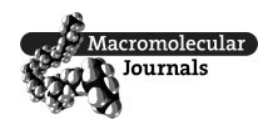




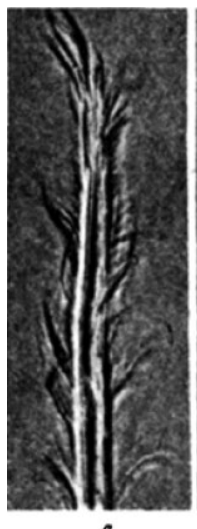

$a$

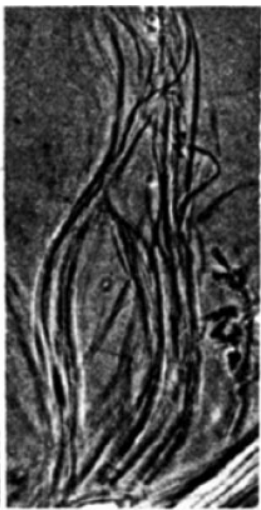

b

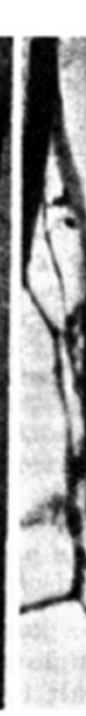

$a$

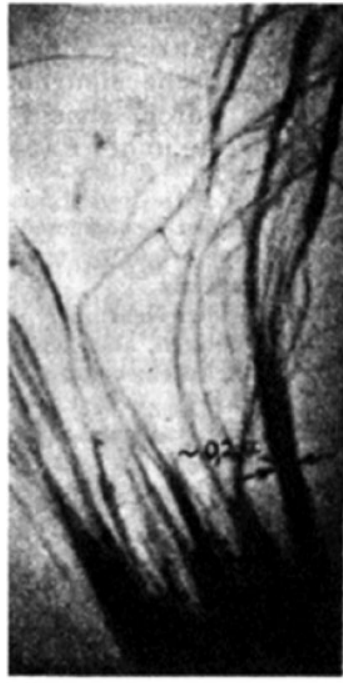

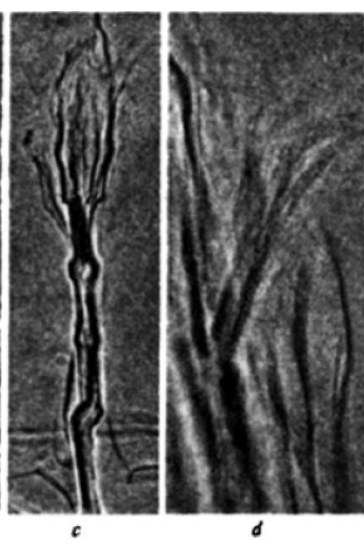

Figure 1. Top: Phase contrast images of various bast fibers after 10 min exposure to ultrasound. a) Ramie magnification $\times 325, b$ ) hemp magnification $\times 325$, c) flax magnification $\times 325$, d) flax magnification $\times 730$. Bottom: electron images (magnification $\times 14$ ooo) of ultrasonicated a) ramie and b) hemp. Obtained from Wuhrmann et al. with permission. ${ }^{[28]}$ Copyright 1946, Springer Verlag.

advanced fiber composites as many of the other applications have been reviewed recently. ${ }^{[7]}$

\section{Cellulose Production in Bacteria}

\subsection{Metabolic Pathway of Cellulose-Producing Bacteria}

For an extensive review on the strains of celluloseproducing bacteria, the readers are referred to Chawla et al. ${ }^{[35]}$ and Shoda and Sugano. ${ }^{[36]}$ The most commonly studied model bacterium for the production of BC is Acetobacter (now Gluconoacetobacter) xylinum due to its ability to produce cellulose from a wide range of carbon/ nitrogen sources. ${ }^{[31]}$ The Acetobacter strains are gramnegative, aerobic, and exist as straight, slightly bent rods or ellipsoidal in the range of $0.6 \mu \mathrm{m} \times 4 \mu \mathrm{m} \cdot{ }^{[37]} \mathrm{Gram}$-negative species such as Agrobacterium, ${ }^{[38]}$ Achromobacter, ${ }^{[39]}$ Aerobacter, ${ }^{[40]}$ Enterobacter, ${ }^{[41]}$ Sarcina, ${ }^{[40]}$ Rhizobium, ${ }^{[39]}$ Pseudomonas, ${ }^{[38]}$ Salmonella, ${ }^{[42]}$ and Alcaligenes ${ }^{[43]}$ have also been found to produce cellulose. However, some Grampositive species such as Gluconoacetobacter hansenii can synthesize cellulose as well. ${ }^{[44]}$ The cellulose yield of various cellulose-producing bacteria is summarized in Table 1.

Cellulose-producing bacteria, such as A. xylinum, operate in the pentose-phosphate cycle or the Krebs cycle, depending on the physiological state of the cell coupled with gluconeogenesis. ${ }^{[45]}$ The pentose-phosphate cycle involves the oxidation of carbohydrates and the Krebs cycle involves the oxidation of acetate-derived carbohydrates, fat, and proteins, such as oxalosuccinate and $\alpha$-ketoglutarate. However, A. xylinum is not able to metabolize glucose anaerobically because it lacks phosphofructose kinase, which is required for glycolysis. ${ }^{[3]}$ Numerous authors have reported the biosynthesis of cellulose by A. xylinum. ${ }^{[46-53]}$ The biosynthesis of cellulose is a multi-step reaction involving individual enzymes, catalytic complexes, and regulatory proteins. It contains four key enzymatic steps when glucose is used as carbon source (Figure 2); they are: i) phosphorylation of glucose by glucokinase ii) isomerization of glucose-6-phosphate (Glc-6-P) to glucose-1-phosphate (Glc-1-P) by phosphoglucomutase, iii) synthesis of UDPglucose (UDPGlc) by UDPG-pyrophosphorylase (UGPase), and iv) cellulose synthase reaction. UDPGlc, which is common in many organisms, is the direct cellulose precursor. UGPase is thought to play an important role in cellulose synthesis since it is approximately 100 times more active in cellulose producers than that of noncellulose producing bacteria. ${ }^{[54]}$ When disaccharides, such as sucrose and maltose, are used as carbon source for cellulose-producing bacteria, the biosynthesis of $\mathrm{BC}$ starts with the hydrolysis of disaccharides into monosaccharides, such as glucose and fructose. Although pathways of UDPGlc are relatively well known, the molecular mechanisms of glucose polymerization into long and unbranched cellulose chains are still elusive to scientists. ${ }^{[54]}$

Cyclic diguanylic acid (c-di-GMP) also plays an important role in the synthesis of $B C$. It is an allosteric activator for the cellulose synthase. In the absence of c-di-GMP, cellulose synthase stays inactive or exhibits low enzyme activity. ${ }^{[45,55]} \mathrm{c}$-di-GMP binding protein is a membrane protein, which is structurally associated with the cellulose synthase; $90 \%$ of the cellular c-di-GMP is reversibly bound by the c-di-GMP binding protein. The equilibrium between bound and free c-di-GMP is modulated by the intracellular potassium concentration. ${ }^{[45,55-57]}$

Cellulose is synthesized in microorganisms in two intermediary steps: i) the formation of 1,4- $\beta$-glucan chains 
Table 1. The BC yields of various cellulose-producing bacteria. Adapted from Chawla et al. ${ }^{[35]}$

\begin{tabular}{|c|c|c|c|c|}
\hline Bacteria & Carbon source & Supplement & $\begin{array}{l}\text { Culture time } \\
{[\mathrm{h}]}\end{array}$ & $\begin{array}{c}\text { Yield } \\
{\left[\mathrm{g} \mathrm{L}^{-1}\right]}\end{array}$ \\
\hline A. xylinum BRC 5 & Glucose & Ethanol + oxygen & 50 & 15.30 \\
\hline G. hansenii & Glucose & Oxygen & 48 & 1.72 \\
\hline G. hansenii & Glucose & Ethanol & 72 & 2.50 \\
\hline Acetobacter sp. V6 & Glucose & Ethanol & 192 & 4.16 \\
\hline Acetobacter sp. A9 & Glucose & Ethanol & 192 & 15.20 \\
\hline A. xylinum BPR2001 & Molasses & & 72 & 7.82 \\
\hline A. xylinum BPR2001 & Fructose & Agar oxygen & 72 & 14.10 \\
\hline A. xylinum BPR2001 & Fructose & Agar & 56 & 12.00 \\
\hline A. xylinum ssp. sucrofermentans BPR2001 & Fructose & Oxygen & 52 & 10.40 \\
\hline A. xylinum ssp. sucrofermentans BPR2001 & Fructose & Agar oxygen & 44 & 8.70 \\
\hline A. Xylinum E25 & Flucose & & 168 & 3.50 \\
\hline G. xylinus $\mathrm{K} 3$ & Mannitol & Green tea & 168 & 3.34 \\
\hline G. xylinus IFO 13773 & Glucose & Lignosulfonate & 168 & 10.10 \\
\hline A. xylinum NUST4.1 & Glucose & Sodium alginate & 120 & 6.00 \\
\hline G. xylinus IFO 13773 & Molasses & & 168 & 5.76 \\
\hline Gluconacetobacter sp. RKY5 & Glycerol & & 144 & 5.63 \\
\hline
\end{tabular}

and ii) the assembly and crystallization of cellulose chains. The rate-limiting step is the assembly and crystallization of cellulose. ${ }^{[58]} \mathrm{BC}$ is formed between the outer and cytoplasm membranes of the cell (Figure 2) ${ }^{[59]}$ The cellulose molecules are first synthesized inside the bacteria. These molecules are then spun through cellulose export components to form protofibrils, which are approximately 2-4 $\mathrm{nm}$ in diameter. A ribbon shaped microfibril of approximately $80 \mathrm{~nm}$ is assembled from these protofibrils. ${ }^{[5]}$ The biosynthesis of cellulose is catalyzed by cellulose synthase, which

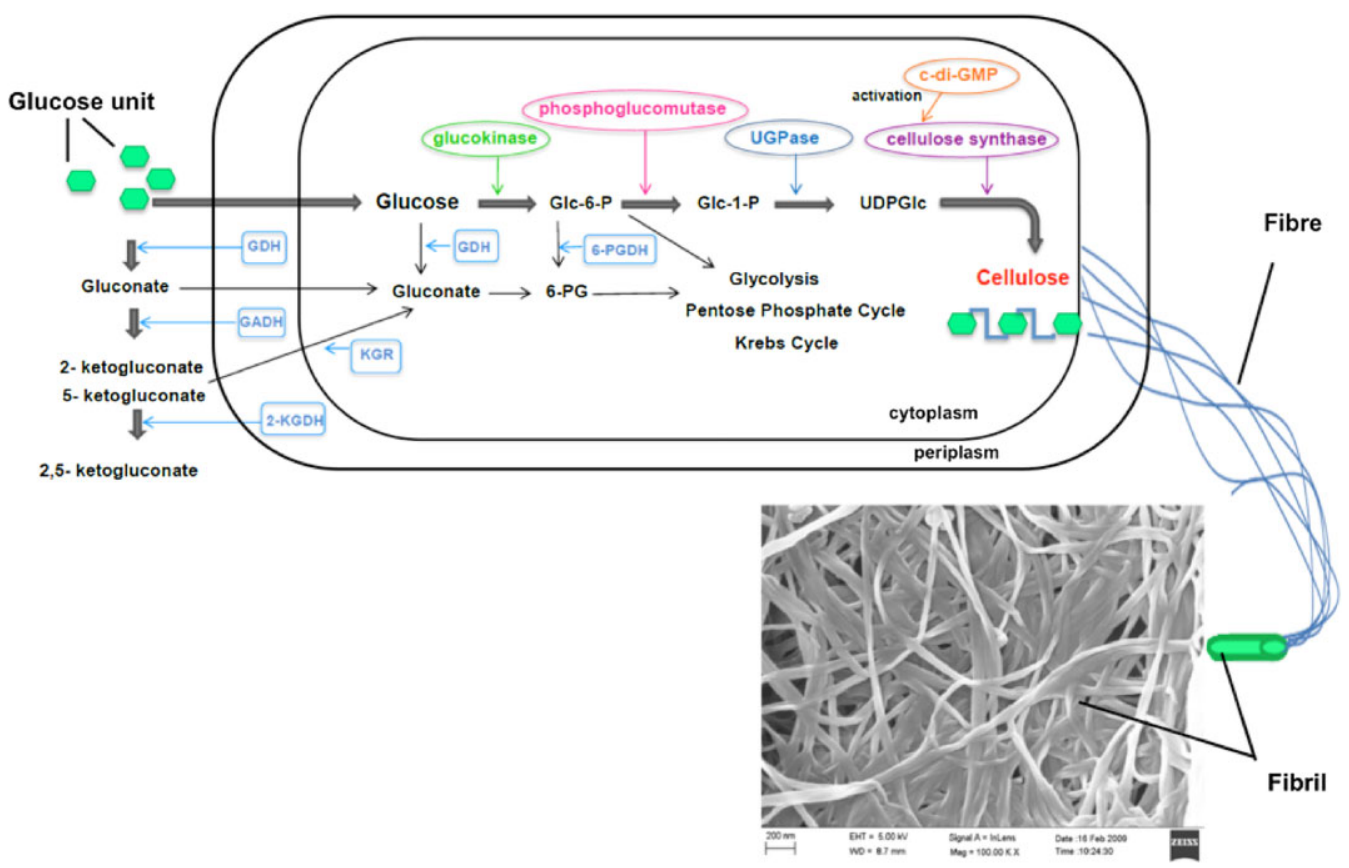

Figure 2. A schematic showing the major metabolic pathways of A. xylinum and the assembly of cellulose molecules into nanofibrils.

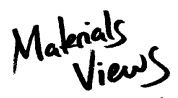

www.MaterialsViews.com 
polymerizes the glucose units into the 1,4- $\beta$-glucan chains. However, the polymerization mechanism of glucan chains from glucose monomers is not yet well understood. One plausible hypothesis is that the polymerization of the 1,4- $\beta$ glucan contains a lipid intermediate, where glucose is first transferred from UDPglc to a lipid molecule in the plasma membrane forming a lipid-glucose intermediate through glycosyltransferase. ${ }^{[60]}$ Another hypothesis was suggested by Brown and Saxena, ${ }^{[58]}$ which does not involve a lipid intermediate. The glucose residues are attached onto the non-reducing end of the polysaccharide, which takes place in the extracytoplasmic space during the polymerization of 1,4- $\beta$-glucan.

\subsection{Genetic Pathway of Acetobacter}

Bacterial cellulose is synthesized by cellulose synthesis operon, which is a functional unit of genomic DNA containing multiple genes. Acetobacter cellulose synthesis operon (acs $\mathrm{ABCD}$ ) and $\mathrm{BC}$ synthesis operon (bcs $\mathrm{ABCD}$ ) are two homologous functional units that encode the essential proteins for cellulose synthesis in A. xylinum ATCC 53582 and 1306-3, respectively. ${ }^{[61,62]}$ Cellulose synthase, which synthesizes cellulose from UDP-glucose, encodes three (acs $\mathrm{AB}, a c s \mathrm{C}$, and $a c s \mathrm{D})$ or four (bcs $\mathrm{A}, b c s \mathrm{~B}, b c s \mathrm{C}$, and $b c s \mathrm{D}$ ) subunits. ${ }^{[63,64]}$ The first gene of the $b c s \mathrm{ABCD}$ operon, $b c s \mathrm{~A}$, encodes the catalytic subunit of cellulose synthase and binds to UDPglc. The second gene, bcsB, encodes the regulatory subunit of cellulose synthase that binds to cdi-GMP. It also plays an important role as second messenger and activates the cellulose synthesis process. ${ }^{[61]}$ acs $\mathrm{A}$ and acs $B$ encode a single polypeptide that has both substrate binding and activator-binding regions. However, the functions of $a c s C / b c s C$ and $a c s D / b c s D$ have not been clarified yet. $a c s C / b c s C$ encodes proteins that are similar to the proteins involved in membrane channels or pore formation, which suggests that acsC/bcsC is responsible for the formation of pores to secrete cellulose. ${ }^{[62]}$ Deactivation of acs $\mathrm{A}, \mathrm{acs} \mathrm{B}$ and acs $\mathrm{C}$ blocks the synthesis of $\mathrm{BC}$ completely, whilst the deactivation of acs $\mathrm{D}$ decreases cellulose production by $40 \%{ }^{[58,62]}$ This suggests that acsD controls the crystallization of cellulose into nanofibrils. Recently, $\mathrm{Hu}$ et al. ${ }^{[65]}$ determined the structure of $a c s D$, which showed an exquisite cylindrical shape with a right-hand twisted dimer interface on the cylinder wall that is formed by a functional octamer unit. They suggested that acsD could provide passageways for extruding glucan chains.

The upstream region of the operon has two genes; cmcax and ccp $A x$, respectively (see Figure 3). CMCax protein, which is coded by the cmcax gene, encodes endo- $\beta$-1,4-glucanase, which has cellulose hydrolyzing activity. It enhances cellulose synthesis. ${ }^{[66-68]}$ However, the functions of CMCax in cellulose biosynthesis have not been identified. Kawano et al. ${ }^{[69]}$ suggested that CMCax from A. xylinum could

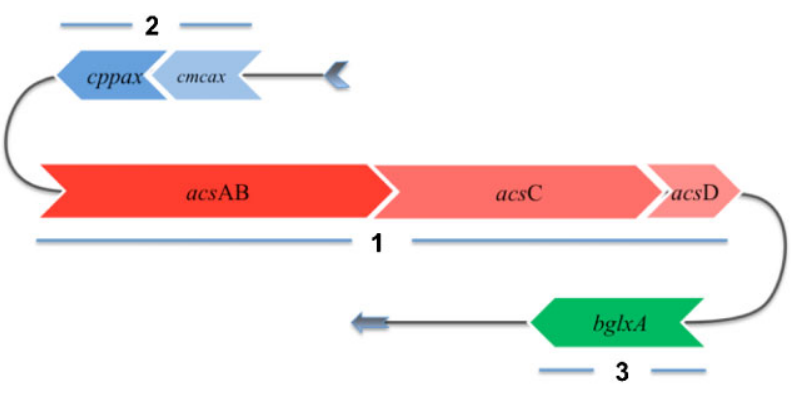

Figure 3. A schematic diagram showing the genetic pathway of A. xylinum ATCC 53582. Regions 1, 2, and 3 represent cellulose synthase operon, upstream, and downstream of the operon, respectively.

influence in cellulose ribbon assembly according to electron microscopy analysis, which revealed that the cellulose ribbons secreted from the CMCax overproducing strain were dispersed compared with those from the wild type strain. The other protein in the upstream region of acs operon is CcpAx. This protein is essential for the production and production enhancement of $B C$. The protein encoded by ccpAx has a complementing function ${ }^{[66]}$ but the nature of this function remains to be elucidated. Sunagawa et al. ${ }^{[0]}$ have also recently shown that $C c p A x$ plays a critical role in localization of the cellulose synthesizing complexes. They suggested that $\operatorname{CcpAx}$ could function as a mediator of protein-protein interactions.

Coucheron ${ }^{[71]}$ reported that the insertion sequence of an IS1031 element upstream of the start of the transcription of this operon resulted in cellulose deficiency in the mutant strain. This implies that the upstream region of the operon may be important for the synthesis of $\mathrm{BC}$. The downstream region contains the gene $b g l x A$ that encodes $\beta$-glucosidase, which hydrolyzes more than three $\beta$-1,4-glucose units. It was observed that the disruption of the bglxA gene causes a decrease in BC production. ${ }^{[63]}$ Kawano et al. ${ }^{[72]}$ suggested a regulation mechanism of CMCax expression in a noncellulose producing mutant of A. xylinum. They used an enzyme assay and real-time quantitative reverse transcriptase polymerase chain reaction (qRT-PCR) in their study. The authors also investigated the expression of the cmcax gene in a wild-type strain by real-time qRT-PCR and demonstrated that gentiobiose induced $C M C a x$ expression and also stimulates $C M C a x$ activity. This suggests that $\mathrm{BC}$ production in A. xylinum is regulated by the gentiobiose concentration in the culture.

\section{Fermentative Production of BC}

Bacterial cellulose production and productivity for bacteria is mainly affected by the culturing conditions, such as the 
composition of the culture medium, environmental factors, such as $\mathrm{pH}$, temperature, dissolved oxygen content, and the type of cultures used (static or agitated fermenters). The optimal design of both medium and culturing conditions is important for the growth of cellulose producing bacteria and this will then stimulate the formation and production of $\mathrm{BC}$.

\subsection{Composition of Culture Media}

The carbon source used for the culturing of cellulose producing bacteria is one of the most important factors affecting the BC yield. Various carbon sources including monosaccharides, oligosaccharides, organic acids, alcohols, and sugar alcohols, have been studied to increase BC production up to now..$^{[2,73-80]}$ Jonas and Farah $^{[24]}$ compared the effect of carbon source on the BC yield. Numerous mono-, di-, polysaccharides, alcohols (ethanol, glycerol, and ethylene glycol), organic acids (citrate, succinate, and gluconate), and other compounds (glucono-lactone and O-methyl-glucose) have been studied. They reported that the preferred carbon sources for BC production were $\mathrm{D}$-arabitol and D-mannitol, which resulted in a 6.2- and 3.8-fold greater BC yield, respectively, compared to glucose.

Pourramezan et al. ${ }^{[81]}$ examined the culture conditions for BC production by Acetobacter sp. 4B-2. Sucrose was identified as the best substrate, which produced the highest $\mathrm{BC}$ yield followed by glucose, xylose, and lactose. The rate of sucrose consumption (80\%) was lower than that of glucose (93\%). This was suggested as the reason for the highest BC yield in the presence of sucrose. Coban and Biyik ${ }^{[82]}$ investigated effect of various carbon and nitrogen sources on cellulose production of $A$. lovaniensis HBB5. Glucose and yeast extract combination in Hestrin and Schramm (HS) medium gave the highest yield of $0.04 \mathrm{~g} \mathrm{~L}^{-1}$.

Mikkelsen et al. ${ }^{[78]}$ investigated the effect of six different carbon sources, namely glucose, glycerol, mannitol, fructose, sucrose, and galactose, respectively, on $B C$ production by Gluconacetobacter xylinus ATCC 53524. The BC yields obtained using different carbon sources were determined in $12 \mathrm{~h}$ time intervals over $96 \mathrm{~h}$ experimental period. Although the most productive carbon source for BC production varied depending on the time courses of the experiment, sucrose gave the highest $\mathrm{BC}$ yield $\left(3.83 \mathrm{~g} \mathrm{~L}^{-1}\right)$ at the end of the period and was followed by glycerol, mannitol, glucose, and fructose, respectively. Galactose was found to be the least suitable carbon source. These results are attributed to the ability of bacteria to synthesize glucose from carbon sources. Mannitol, fructose, or glucose showed consistent rates of cellulose production since they are effectively transported through the cell membrane (mannitol is converted to first fructose). The same group of authors observed that transformation of galactose to cellulose by the bacteria was not as efficient because of the inefficient uptake by the bacteria from the medium. In the first $84 \mathrm{~h}$ of the $96 \mathrm{~h}$ experiment, sucrose resulted the second lowest $\mathrm{BC}$ yield. The reason for this was that sucrose could not be utilized directly but needs to be hydrolyzed into glucose and fructose in the periplasm. Nonetheless, the microscopic and macromolecular properties of BC produced from all carbon sources are very similar. All samples exhibited similar degrees of crystallinity of between 80 and $90 \%$ and even the $I_{\alpha} / I_{\beta}$ ratios were found to be identical.

Whilst glucose is the most widely used carbon source for the cultivation of cellulose-producing bacteria, the formation of gluconic acid can be problematic. Gluconic acid is formed as a by-product during the cultivation of bacteria when glucose is used and, therefore, decreases the $\mathrm{pH}$ of the culture medium, which in turn affects the production of cellulose. Therefore, the glucose concentration for BC production is an important parameter. Masaoka et al. ${ }^{[73]}$ studied the BC yield of A. xylinum IFO 13693 at various glucose concentrations of $6,12,24$, and $48 \mathrm{~g} \mathrm{~L}^{-1}$, respectively. It was found that the BC yield decreases with increasing initial glucose concentration in the culture medium. At high initial glucose concentrations of 24 and $48 \mathrm{gL}^{-1}$, the gluconic acid concentration increases during the cultivation period. Since the total BC and gluconic acid production equals the amount of consumed glucose, this suggests that if glucose is not used for cellulose synthesis, it is metabolized via gluconic acid to other substances. The effect of glucose concentration on BC production by Acetobacter sp. V6 was also investigated by Son et al. ${ }^{[76]}$ under shaking culture conditions. BC production was enhanced with increasing amounts of glucose of up to $1.5 \%$ but decreased when it was above $2 \%$. Keshk and Sameshima ${ }^{[77]}$ reported that the maximum BC yield by $A$. xylinum was obtained at $1 \%$ concentration of glucose whereas, the minimum BC yield was observed at both 2 and $3 \%$ concentrations. As initial high glucose concentrations resulted in low yields of $\mathrm{BC}$, a low glucose concentration is desirable for batch cultures. ${ }^{[73]}$

Glycerol has been used in several studies for BC production by Acetobacter strains. ${ }^{[73,77,78]}$ The BC cellulose yields obtained from media using glycerol as carbon source, were lower than that from glucose containing static culture media. Jung et al. ${ }^{[44]}$ investigated the production of $\mathrm{BC}$ in shake culture using various carbon sources including glucose and glycerol. The highest BC production $\left(2.16 \mathrm{~g} \mathrm{~L}^{-1}\right)$ was obtained in glycerol containing medium. When maltose was used as a carbon source, the BC yield was 10 times lower than that of a culture medium containing glucose as the carbon source. ${ }^{[73]}$ Matsuoka et al. ${ }^{[83]}$ have also observed that when lactate was present in the culture medium, the growth of A. xylinum ssp. sucrofermentous BPR2001 in an agitated culture increased and the BC

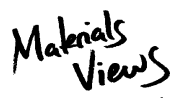

www.MaterialsViews.com

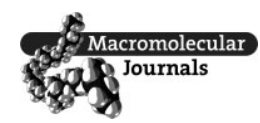


yield was enhanced by approximately $4-5$ times. It was postulated that lactate serves as an accelerator to drive the tricarboxylic acid (TCA) cycle, as well as an energy source for A. xylinum ssp. sucrofermentous BPR2001. These two effects may have resulted in more rapid cell growth and higher BC yield.

Ruka et al. ${ }^{[80]}$ studied several types of media that have been previously reported in literature to grow G. xylinus. The media studied included HS medium ${ }^{[84]}$ and those suggested by Yamanaka et al., ${ }^{[85]}$ Zhou et al., ${ }^{[86]}$ Son et al., ${ }^{[76]}$ and corn steep liquor (CSL) ${ }^{[87]}$ with slight modifications to exclude environmentally damaging compounds, such as zinc sulfate hepahydrate and copper sulfate pentahydrate. The medium suggested by Son et al. ${ }^{[76]}$ was further modified to include $2(\mathrm{v} / \mathrm{v}) \% \mathrm{CSL}$. All the different culture media yielded BC with similar cellulose $\mathrm{I}_{\alpha}$ content and crystallite size. However, the degree of crystallinity of the BC produced by the bacteria varied only marginally irrespective of the medium used. Unfortunately, the authors did not provide a reason for this. Nonetheless, the $\mathrm{BC}$ production is high if produced in Yamanaka et al. ${ }^{[85]}$ and Zhou et al. ${ }^{[86]}$ media due to the high carbon source concentration. The Zhou medium was more effective than CSL although their chemical compositions are very similar except for the trace elements (which included various Fe, Zn, $\mathrm{Mn}, \mathrm{Cu}$, and $\mathrm{Na}$ based components). This showed that the trace elements in the CSL media are of no benefit. Son medium was surprisingly effective in the production of BC despite its low carbon source concentration, which was even lower than that of the HS medium. From these results, the authors postulates that the medium suggested by Son et al. ${ }^{[76]}$ could be a cost-effective medium for BC production.

Bae and Shoda ${ }^{[88]}$ investigated the optimum culture medium for the production of BC. The authors used a BoxBehnken design for optimizing the concentration of various components within the culture medium. The authors reported that a $B C$ yield of $14 \mathrm{~g} \mathrm{~L}^{-1}$ can be obtained after $72 \mathrm{~h}$ fermentation time when using a culture medium containing $4.99 \mathrm{wt} \%$ of fructose, $2.85 \mathrm{wt} \% \mathrm{CSL}$, which is a viscous liquid by-product of corn wet milling, rich in amino acids, vitamins and other minerals, 28.33 wt\% dissolved oxygen content and $0.38 \mathrm{wt} \%$ agar. Another study ${ }^{[89]}$ by the same authors showed that changing the carbon source to $\mathrm{H}_{2} \mathrm{SO}_{4}$ treated molasses, a viscous by-product from sugarcane refining, increased the BC yield by $76 \%$ compared to neat molasses in a culture containing A. xylinum BPR2001.

The addition of ethanol into the culture medium was found to be beneficial for the production of BC. Ethanol can suppress the spontaneous mutation of cellulose producing bacteria into cellulose non-producing mutants, ${ }^{[90]}$ which can appear under agitated culture conditions. In addition to this, ethanol can also used as additional carbon source for $G$. hansenii. ${ }^{[90]}$ The BC yield by $G$. hansenii increased from 1.30 to $2.31 \mathrm{~g} \mathrm{~L}^{-1}$ by addition of 1 vol\% ethanol. Son et al. ${ }^{[91]}$ also studied the effect of ethanol on the BC production of Acetobacter sp. A9 strain. The addition of $1.4 \mathrm{vol} \%$ ethanol to the culture medium increased the BC yield by $400 \%$ $\left(15.2 \mathrm{~g} \mathrm{~L}^{-1}\right)$ compared to culture medium, which did not contain ethanol. This significant increase in BC yield can be attributed to the aforementioned benefits of ethanol.

A nitrogen source is also important to cellulose producing bacteria as it can provide not only amino acids but also vitamins and mineral salts for the bacteria. Yeast extract and peptone, which are the basic components of the model medium developed by Hestrin and Schramm, ${ }^{[84]}$ are the most preferred nitrogen sources. However, the most recommended nitrogen source for agitated cultures is

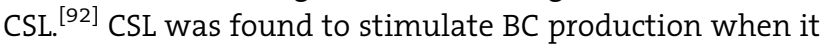
was added in low concentrations ( 0.15 vol\%) to the medium containing $4(\mathrm{w} / \mathrm{v}) \%$ of fructose ${ }^{[83]}$ The lactate in CSL, which is absent in other nitrogen sources, is the main reason for this enhanced BC yield. ${ }^{[83]}$

Son et al. ${ }^{[91]}$ studied various nitrogen sources, which were added separately to the medium in concentrations of $0.5 \%(\mathrm{w} / \mathrm{v})$ to assess their affects on BC production by Acetobacter sp. A9. Yeast extract was the best source resulting in a yield of $2.87 \mathrm{~g} \mathrm{~L}^{-1}$ followed by polypeptone $\left(2.65 \mathrm{~g} \mathrm{~L}^{-1}\right)$ and CSL $\left(2.59 \mathrm{~g} \mathrm{~L}^{-1}\right)$. Although when yeast extract is used in the medium it produces the highest BC yield, it is economically unfeasible. Results indicated that CSL, which is a cheaper organic nitrogen source, maybe used instead to successfully substitute for yeast extract in the medium.

Ramana et al. ${ }^{[93]}$ also studied the affect of various nitrogen sources on the production of BC by A. xylinum. When casein hydrolyzate was used as the nitrogen source in the culture medium, a BC yield of $5 \mathrm{~g} \mathrm{~L}^{-1}$ was obtained, compared to peptone as nitrogen source, which yielded only $4.8 \mathrm{~g} \mathrm{~L}^{-1}$ of $\mathrm{BC}$. The results obtained by Matsuoka et $a .^{[83]}$ also showed that the addition of extra nitrogen supports the biomass and BC production. Studies on the influence of vitamins, such as pyridoxine, nicotinic acid, $p$-aminobenzoic acid, and biotin, on $\mathrm{BC}$ production showed that these vitamins were the most stimulating vitamins for BC production. ${ }^{[83,94]}$ However, pantothenate and riboflavin have been shown to decrease the $\mathrm{BC}$ productivity. ${ }^{[83,94]}$

In addition to $\mathrm{BC}$ yield, the quality of $\mathrm{BC}$, namely the crystallinity of $B C$, is important as it is postulated to affect the mechanical properties of $\mathrm{BC}$. The use of molasses instead of glucose was investigated by X-ray diffraction. The results showed that the use of molasses does not affect the degree of crystallinity of BC $\left(\chi_{c}\right)$ remarkably. A $\chi_{c}$ of $88 \%$ was obtained for BC cultured with glucose as the carbon source compared to $84 \%$ in with molasses as the carbon source. ${ }^{[96]}$ No significant changes in $\chi_{c}$ were observed when saccharified food waste was used as carbon source. Saccharified food waste is produced by the enzymatic saccharification of food wastes, which produces a 
sacchoragenic liquid that can used as medium for the production of BC. $\chi_{\mathrm{c}}$ of $\mathrm{BC}$ produced by A. xylinum $\mathrm{KJ} 1$ in Hestrin and Schramm medium under static culture was found to be $89.7 \%$ whilst a $\chi_{c}$ of $84.1 \%$ was obtained when saccharified food waste was used as the carbon source ${ }^{[97]}$ In a separate study however, rice bark, which is potentially a nutrient source for bacterial fermentation process because it contains minerals, cellulose, and hemicelluloses as well as residual starch, was shown to reduce $\chi_{c}$ from $56 \%$ (glucose as the carbon source) to only $28 \%$ (rice bark as the carbon source) ${ }^{[98]}$ However, the authors failed to mention why this was the case.

\subsection{Bioprocess Parameters for the Production of BC}

The main environmental parameters affecting the growth of cellulose producing bacteria and $\mathrm{BC}$ production are $\mathrm{pH}$, temperature, and dissolved oxygen content. Microorganisms rapidly respond to these factors in terms of induction and repression of protein synthesis and changes in cell morphology.

\subsubsection{Influence of $\mathrm{pH}$ on $\mathrm{BC}$ Production}

It has been shown that the optimum $\mathrm{pH}$ for the growth of bacteria and production of $\mathrm{BC}$ depends on the particular strain of bacteria used but is usually in the range of 4-7. ${ }^{\text {92] }}$ $\mathrm{BC}$ production was observed over broad $\mathrm{pH}$ ranges of between 4.5 and 7.5 with the highest BC production occurring at $\mathrm{pH} 6.5 .^{[91]}$ However, the industrial production of BC membranes for biomedical applications, namely Biofill and Gengiflex, was conducted at low $\mathrm{pH}$ of between $\approx 4$ and 4.5 as this does avoid contamination of the medium during $\mathrm{BC}$ culturing. ${ }^{[24]}$ Whilst $\mathrm{BC}$ can be produced over wide ranges of $\mathrm{pH}, \chi_{\mathrm{c}}$ is independent of the $\mathrm{pH}$ of the culture medium. ${ }^{[99]}$ It should also be noted that the $\mathrm{pH}$ of the culture medium could decrease as a function of time due to the accumulation of secondary metabolites, such as gluconic, acetic, or lactic acids that are produced during the consumption of sugars and nitrogen sources. Therefore, maintaining the $\mathrm{pH}$ of the culture medium for the maximum yield of BC is important. In this context, CSL can be added into the culture medium as a buffer to maintain the $\mathrm{pH}$ of the culture medium. ${ }^{[100]}$ However, the viscous CSL increases the viscosity of the medium, which could cause inhomogeneous mixing of culture components within the medium.

\subsubsection{Influence of Temperature on BC Production}

The influence of temperature (from 20 to $40^{\circ} \mathrm{C}$ ) on the yield of $\mathrm{BC}$ produced by Acetobacter sp. A9 in Hestrin and Schramm medium was investigated by Son et al. ${ }^{[91]}$ The optimum temperature for $\mathrm{BC}$ production was found to be $30^{\circ} \mathrm{C}$. Whilst lowering the culture temperature to $25^{\circ} \mathrm{C}$ did not significantly decrease the $\mathrm{BC}$ yield compared to $30^{\circ} \mathrm{C}$, increasing the temperature to $35^{\circ} \mathrm{C}$ reduces the $\mathrm{BC}$ yield. ${ }^{[61]}$ The morphology and crystal structure was affected by cultivation temperature. Hirai et al. ${ }^{[101]}$ reported that BC produced by A. xylinum ATCC 23769 in HS medium at $4{ }^{\circ} \mathrm{C}$ was band shaped with a cellulose II structure while BC produced at $28^{\circ} \mathrm{C}$, on the other hand, were cellulose I ribbons. Similar findings were also reported by Zeng et al., ${ }^{[9]}$ whereby cellulose I was produced by A. xylinum BPR2001 in a medium composed of $20 \mathrm{gL}^{-1}$ fructose, $3.3 \mathrm{~g} \mathrm{~L}^{-1}\left(\mathrm{NH}_{4}\right)_{2} \mathrm{SO}_{4}, 20 \mathrm{~g} \mathrm{~L}^{-1}$ yeast extract, $1 \mathrm{~g} \mathrm{~L}^{-1} \mathrm{KH}_{2} \mathrm{PO}_{4}$, and $0.122 \mathrm{~g} \mathrm{~L}^{-1} \mathrm{MgSO}_{4} \cdot 7 \mathrm{H}_{2} \mathrm{O}$ when the culture temperature was maintained between 25 and $30^{\circ} \mathrm{C}$.

\subsubsection{Influence of Oxygen on BC Production}

The dissolved oxygen content in the culture medium is important for cell metabolism and both the yield and quality of BC depend on the dissolved oxygen content. ${ }^{[102]}$ However, it was reported that high dissolved oxygen content in the medium would result in an increase in gluconic acid concentration. ${ }^{[103]}$ This would in turn affect the cell viability, which ultimately reduces the yield of BC. Low dissolved oxygen content, on the other hand, impedes bacteria growth and production of BC. In batch-fed cultures, maximum $B C$ concentration was reported at $10 \%$ saturation of dissolved oxygen. ${ }^{[104]}$

\section{Genetic Modification of Bacteria to Enhance BC Production}

When glucose or sucrose is used as carbon source for $A$. xylinum, the main product is not cellulose but ketogluconate, which is produced via oxidation of the carbon source. ${ }^{[73]}$ In order to limit the conversion of glucose into ketogluconate and increase its conversion into cellulose, ketogluconate-negative Acetobacter strains were isolated. ${ }^{[105]}$ The authors reported that the BC yield increased from $1.8 \mathrm{~g} \mathrm{~L}^{-1}$ (the parent strain) to $3.3 \mathrm{~g} \mathrm{~L}^{-1}$ after $10 \mathrm{~d}$ of cultivation whilst the consumption of glucose by the mutant strain decreased from $22.6 \mathrm{gL}^{-1}$ for the parent strain to $7.3 \mathrm{~g} \mathrm{~L}^{-1}$. This decrease in glucose consumption is attributed to the inhibition of the metabolic pathway that converts glucose to ketogluconate.

Bae et al. ${ }^{[06]}$ modified A. xylinum BPR2001 genetically with the aim to compare the production and structural characteristics of the BC formed by dgc1-disrupted mutants with those produced by the parental strain BPR 2001. The gene modified, $d g c 1$, plays an important role in activating $B C$ synthesis, which catalyzes the synthesis of c-di-GMP. Therefore, it was expected that the disruption of dgc1 should decrease $B C$ production. Contrary to what the authors expected, the BC production of dgc1-disrupted mutants remained approximately the same as for the

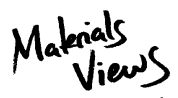

www.MaterialsViews.com

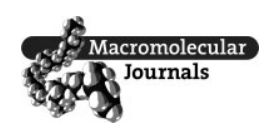


parent strain, in both static and shake flask cultures. The growth rate of dgc1-disrupted mutants was found to be slower than that of the parental strain. This could explain why $d g c 1$ disruption might not have affected the overall BC yield in static or shake flask cultures. In a stirred tank reactor, however, the BC yield of dgc1-disrupted mutants was found to be $36 \%$ higher than that of the parent strain. ${ }^{[106]}$ The study shows that although c-di-GMP synthesis is essential for cellulose synthase activation, disruption of the $d g c 1$ gene, which catalyzes c-di-GMP formation, was probably not fatal for BC synthesis. It was hypothesized that $d g c 2$ and $d g c 3$, which have similar functions to those of $d g c 1$, complemented or even enhanced the $\mathrm{BC}$ production. Tal et al., ${ }^{[107]}$ on the other hand, observed a decrease in $B C$ production when $d g c 1$ was disrupted. The contradictory results reported by Bae et al. ${ }^{[106]}$ and Tal et al. ${ }^{[107]}$ could be due to the short cultivation time used by the latter group to evaluate the final yield of BC.

Gluconoacetobacter xylinus (formerly known as $A$. xylinum) secretes the viscous water-soluble polysaccharide acetan during BC production. ${ }^{[108]}$ The acetan is produced by G. xylinus from UDPGlc, which is also the starting compound (nucleotide sugar) to produce cellulose. Therefore, inhibiting the production of acetan is expected to increase the concentration of UDPGlc, which in turn increases the yield of BC. This approach was taken by Ishida et al., ${ }^{[109]}$ whereby a non-acetan producing mutant strain (EP1) was derived from G. xylinus BPR2001. Contrary to what the authors expected, the BC productivity of EP1 decreased compared to the parent strain in a shake flask culture. Under static conditions, no significant difference in the yield of BC between EP1 and the parental strain was observed. The authors attributed this reduced $B C$ yield in EP1 to the role played by acetan in the culture. The cultivation of EP1 resulted in heterogeneous suspensions containing large flocks of cells and BC in the culture broth. The lack of acetan reduced the viscosity of the culture medium and increases the likelihood of cell and BC coagulation, which led to a decrease in $\mathrm{BC}$ production.

The lack of cellulose hydrolyzing enzymes in human body and the high crystallinity restrict biomedical and biomass conversion applications of BC. ${ }^{[110]}$ Yadav et al. ${ }^{[111]}$ used genetically engineered $G$. xylinus to generate modified cellulose with improved in vivo degradability. The cellulose synthase of $G$. xylinus can utilize both UDP-glucose and UDP- $N$-acetylglucosamine (UDP-GlcNAc) as substrates. ${ }^{[102,112]}$ The presence of GlcNAc enables BC to be susceptible to lysozyme and also disrupts the highly ordered cellulose crystalline structure. In order to utilize this feature, an operon containing three genes from Candida albicans for UDP-GlcNAc synthesis was expressed in G. xylinus to produce activated cytoplasmic UDP-GlcNAc monomers accessible to cellulose synthase to produce a chimeric polymer comprising both glucose and GlcNAc.
X-ray diffraction of the polysaccharide produced by the engineered G. xylinus strain exhibited half the crystallinity of $B C$ produced from non-modified bacteria. The modified BC degraded entirely after $10 \mathrm{~d}$ and was completely undetectable after $20 \mathrm{~d}$ whilst little or no degradation of BC produced from the control strain was observed at either time point. The study presented an exciting development, demonstrating in vivo degradation of a modified BC-based biomaterial.

Kawano et al. ${ }^{[63]}$ cloned $14.5 \mathrm{~kb}$ of the DNA fragments that contain cellulose synthesis related genes in the upstream and downstream regions of the bcs operon in A. xylinum ATCC23769 and ATCC53582. The nucleotide sequences in these fragments contain endo- $\beta$-1,4-glucanase, cellulose complementing protein, cellulose synthase subunits $A B, C$, and $D$, and $\beta$-glucosidase genes. During a 7-d incubation period, ATCC53582 produced five times more BC than ATCC23769. The production of BC continued in ATCC53582 after all the glucose was consumed. This suggests that either gluconic acid was used as carbon source for the production of BC and not solely as energy source or that the glyconeogenesis pathway may be activated. This led the authors to suggest that ATCC23769 uses its energy toward cell growth whilst ATCC53582 uses its energy for $\mathrm{BC}$ production.

As aforementioned, CMCax is important for both cellulose hydrolysis and synthesis. The protein in the upstream region of acs operon is CcpAx, which is suggested to be involved in cellulose crystallization. ${ }^{[113]}$ In order to identify the relationship between the structure and function of these genes, Kawano et al. ${ }^{[114]}$ studied the crystallization of cellulose and its relationship to CMCax in A. xylinum. The authors observed a 1.2-fold increase in the yield of $B C$ when an over-expression of CMCax was induced in A. xylinum. In addition to this, the addition of CMCax protein into the culture medium also increases the production of $\mathrm{BC} .^{[69]}$

Nobles and Brown ${ }^{[115]}$ transferred a partial cellulose synthase operon (acs-ABCD) of G. xylinus into unicellular cyanobacteria (Synechococcus leopoliensis strain UTCC 100). The genes were expressed successfully in this cyanobacterium and so the genetically modified S. leopoliensis produced amorphous cellulose lacking the typical fibrillar structure of BC. Nevertheless, the authors suggested that the non-crystalline nature of this $B C$ might be useful for biofuel production. Shigematsu et al. ${ }^{[116]}$ cloned a gene sequence encoding a putative pyrroloquinoline quinone glucose dehydrogenase from G. xylinus BPR2001. The cloned gene fragment was used to produce a glutamate dehydrogenase (GDH)-deficient mutant strain of BPR2001 (GD-I). The GD-I strain does not produce gluconic acid but it produces $4.1 \mathrm{~g} \mathrm{~L}^{-1}$ of $\mathrm{BC}$ aerobically in a medium containing glucose as carbon source. This BC production of GD-I was approximately two times higher than that of the wild 
strain. The yield coefficient values (grams of BC produced per gram of consumed glucose) of strains GD-I and BPR2001 were found to be 0.1 and 0.06 , respectively.

\section{Bioreactor Systems for BC Production}

Bacterial cellulose is typically produced in static culture. However, the growth of cellulose producing bacteria and the production of cellulose is slow in static cultures, even in the most favorable culture medium. ${ }^{[117]}$ Culture periods can range from $10 \mathrm{~d}$ to 6 weeks, depending on the strain of bacterium used. One plausible explanation for the slow growth rate is the mass transfer of oxygen and nutrients to the bacteria within the pellicles. Nonetheless, one of the earliest efforts of commercialized BC comes in the form of nata-de-coco, an indigenous dessert of the Philippines, which is produced in static cultures. The bacteria are grown in $50 \times 35 \times 10 \mathrm{~cm}^{3}$ plastic vessels. ${ }^{[5]}$ After inoculation with bacteria, the vessels are covered with old newspaper and kept for 8-10 d. Coconut water is used as the culture medium. It is also common practice to add sugar and nitrogen containing compounds, such as ammonium sulfate or diammonium hydrogen phosphate as it could form amino acids for the growth of bacteria. ${ }^{[3]}$ The typical $\mathrm{BC}$ yield in these static cultures is approximately $5 \mathrm{~g} \mathrm{~L}^{-1}$ after $27 \mathrm{~d}$.

In order to reduce the cultivation period, shake cultures can be used. The chemical structure of BC produced in static and shaken conditions is identical. ${ }^{[18]}$ More importantly, a typical 3-4 weeks culture time of bacteria under static condition can be reduced to just 2-4 $d$ under shaken conditions. ${ }^{[117]}$ Within $4 \mathrm{~d}$, a BC yield of $2.5 \mathrm{~g} \mathrm{~L}^{-1}$ was observed. The growth rate of bacteria was also significantly increased. However, the BC yield is still lower than that of static cultures. This is attributed to the drawback of shaken cultures, which promotes the mutation of cellulose producing bacteria into non-cellulose producing mutants. ${ }^{[119]}$ In order to produce $B C$ in a viable manner, bioreactors with novel designs are used to improve production and to reduce the likelihood of mutation of bacteria and more importantly, reducing the labor cost. In the following, we discuss recent advances in bioreactor designs to scale up and enhance the production of $\mathrm{BC}$.

\subsection{Stirred Tank Reactors}

In addition to the tendency of the mutation of bacteria to non-cellulose producing strains, the aforementioned shaking flask culture also suffers from the increase of the viscosity of the culture broth as a result of BC accumulation. ${ }^{[35,36]}$ This causes inhomogeneity of the culture medium and reduced oxygen mass transfer in the culture.
The inhomogeneity of the culture medium can be addressed by using a stirred tank reactor. In addition to this, the doubling time of $A$. xylinum was found increase in submerged conditions ( $4-6 \mathrm{~h}$ ) compared to static condition $(8-10 \mathrm{~d}) .{ }^{[31]}$ Kouda et al. ${ }^{[120]}$ studied the behavior of the culture medium during the mixing of $\mathrm{BC}$ in a stirred tank reactor. The rheological properties of the $\mathrm{BC}$ culture broth were found to be non-Newtonian; shear-thinning behavior was observed. The BC yield is also very dependent on the stirring speed used. By using a stirring speed of $1200 \mathrm{rpm}$, a $B C^{1}$ yield of $\approx 18 \mathrm{gL}^{-1}$ was obtained within $45 \mathrm{~h}$, compared to $\mathrm{BC}$ yields of 13 and $5 \mathrm{gL}^{-1}$, respectively, after $70 \mathrm{~h}$ of culture time at stirring speeds of 800 and $600 \mathrm{rpm}$, respectively. ${ }^{[121]}$ The increase of the BC yield with increasing stirrer speed is a direct result of enhanced volumetric oxygen mass transfer coefficient $\left(k_{\mathrm{L}} \mathrm{a}\right)$ when higher stirring speeds were used. Dudman ${ }^{[117]}$ used a $10 \mathrm{~L}$ stainless steel stirred tank reactor with baffles and a $2.5^{\prime \prime}$ diameter impeller to produce BC. It was observed that when the $A$. acetigenum strain EA-I was used, it tends to form solid mass of growth on the baffles and impeller shaft compared to A. xylinum strain HCC B-155. A BC yield ranging from 1.08 to $1.71 \mathrm{~g} \mathrm{~L}^{-1}$ was obtained within $6 \mathrm{~d}$ of culturing.

When $\mathrm{H}_{2} \mathrm{SO}_{4}$ hydrolyzed molasses was used as the carbon source in a stirred tank reactor, a maximum $\mathrm{BC}^{2}$ yield of $5.3 \mathrm{~g} \mathrm{~L}^{-1}$ was obtained within $72 \mathrm{~h}$ of cultivation compared to $3.01 \mathrm{gL}^{-1}$ for neat molasses. ${ }^{[89,122]}$ This increase in $\mathrm{BC}$ yield is due to the fact that the acid hydrolysis of molasses changes the sugar content in the molasses from fructose-rich to glucose-rich. The strain of bacteria used in this study favors glucose as the main carbon source. ${ }^{[56]}$ In addition to this, adding agar to the culture medium used in a stirred tank reactor also favors the production of $\mathrm{BC}$. A maximum $\mathrm{BC}^{3}$ productivity of $0.261 \mathrm{~g} \mathrm{~L}^{-1} \mathrm{~h}^{-1}$ was obtained when $0.4 \mathrm{wt} \%$ of agar was added. ${ }^{[123]}$ This increase in productivity is postulated to be due to the increased viscosity of the culture medium, which reduced the shear stresses experienced by the bacteria during cultivation. This resulted in the formation of smaller BC flocks, which is advantageous in terms of oxygen and nutrient mass transfer. However, it should be noted that submerged cultures, such as those in stirred tank reactors, still suffer from mutation of bacteria from cellulose producing to non-cellulose producing strains. ${ }^{[21]}$

\footnotetext{
'The strain used in this study was Acetobacter xylinum ssp. surcrofermentans BPR $3001 \mathrm{~A}$ with fructose as the carbon source.

${ }^{2}$ The strain used in this study was Acetobacter xylinum ssp. surcrofermentans BPR 2001.

${ }^{3}$ The strain used in this study was Acetobacter xylinum ssp. surcrofermentans BPR 2001 with fructose as the carbon source.
} 


\subsection{Airlift Bioreactors}

Airlift bioreactors have been widely used in biochemical processes due to their simple design and ease of maintenance. ${ }^{[24,125]}$ However, these reactors are not suitable for viscous fermentation. Chao et al. ${ }^{[126]}$ used an air lift reactor (see Figure 4) with an internal loop to produce BC ${ }^{4}$. A BC concentration of only $2.3 \mathrm{~g} \mathrm{~L}^{-1}$ was obtained after $80 \mathrm{~h}$ of culture time. This poor production of BC was attributed to the limited dissolved oxygen content in the culture medium. Indeed, when oxygen enriched air was used, a BC concentration of $5.63 \mathrm{~g} \mathrm{~L}^{-1}$ was observed within $28 \mathrm{~h}$. A similar study using the same reactor also showed that the accumulation of $\mathrm{BC}$ could result in a decrease in the dissolved oxygen content in the culture medium. ${ }^{[127]}$ The $k_{\mathrm{L}} \mathrm{a}$ of $\mathrm{BC}$ suspension in the reactor was found to decrease when compared to water. ${ }^{[28]} \mathrm{A} k_{\mathrm{L}}$ a value of 150 $\mathrm{h}^{-1}$ was measured for water, however, when the $\mathrm{BC}$ concentrations in water were increased to 0.25 and $0.50 \mathrm{wt}$ $\%$, the $k_{\mathrm{L}}$ a values decreased to 90 and $40 \mathrm{~h}^{-1}$, respectively. For comparison ${ }^{5}$, a $1 \mathrm{wt} \% \mathrm{BC}$ suspension in a conventional stirred tank reactor has a $k_{\mathrm{L}}$ a value of $80 \mathrm{~h}^{-1}$. ${ }^{[121]}$ The operating cost is also an important parameter when it comes to commercialization. Chao et al. ${ }^{[128]}$ compared the estimated energy consumption of an airlift bioreactor and a conventional stirred tank reactor. The authors found that $0.126 \mathrm{~kW} \cdot \mathrm{h}^{-1}$ of energy is required to produce $1 \mathrm{~g} \mathrm{~L}^{-1}$ of $\mathrm{BC}$ in an airlift bioreactor with oxygen enriched air supply, compared to $0.663 \mathrm{~kW} \mathrm{~h}^{-1}$ in a stirred tank reactor.

In order to enhance $k_{\mathrm{L}} \mathrm{a}$, the draft tube in a conventional airlift bioreactor was modified to reduce the bubble size and increase the interfacial area to volume ratio, $a$, in the $k_{L} a$ term. Cheng et al. ${ }^{[129]}$ developed a rectangular wire-mesh draft tube to enhance the oxygen mass transfer in an airlift reactor. When the performance of this modified reactor is compared to a conventional bubble column reactor, the $\mathrm{BC}$ concentration increased approximately five times, from 2.82 to $7.72 \mathrm{~g} \mathrm{~L}^{-1}$. This is attributed to the decrease in bubble coalescence and subdivision of the bubbles into smaller bubbles within the reactor. The $k_{\mathrm{L}} \mathrm{a}$ value of the modified airlift bioreactor increased by 50\% compared to a conventional bubble column reactor.

Another type of modified airlift reactor is a spherical bubble column reactor. This type of reactor has been used by Choi et al. ${ }^{[130]}$ to produce BC. They reported a maximum BC concentration of $6.8 \mathrm{~g} \mathrm{~L}^{-1}$. During the culture process, agar was added into the culture medium to increase the viscosity

${ }^{4}$ The strain used in this study was Acetobacter xylinum ssp. surcrofermentans BPR 2001.

${ }^{5}$ It should be noted that $k_{\mathrm{L}} \mathrm{a}$ is highly dependent Reynolds number. ${ }^{6}$ The strain of bacteria used in this study was Acetobacter xylinum ssp. sucrofermentans BPR2001 with glucose as the carbon source. ${ }^{7}$ The strain of bacteria used was $A$. xylinum $\mathrm{KJ} 1$ with glucose as the carbon source.

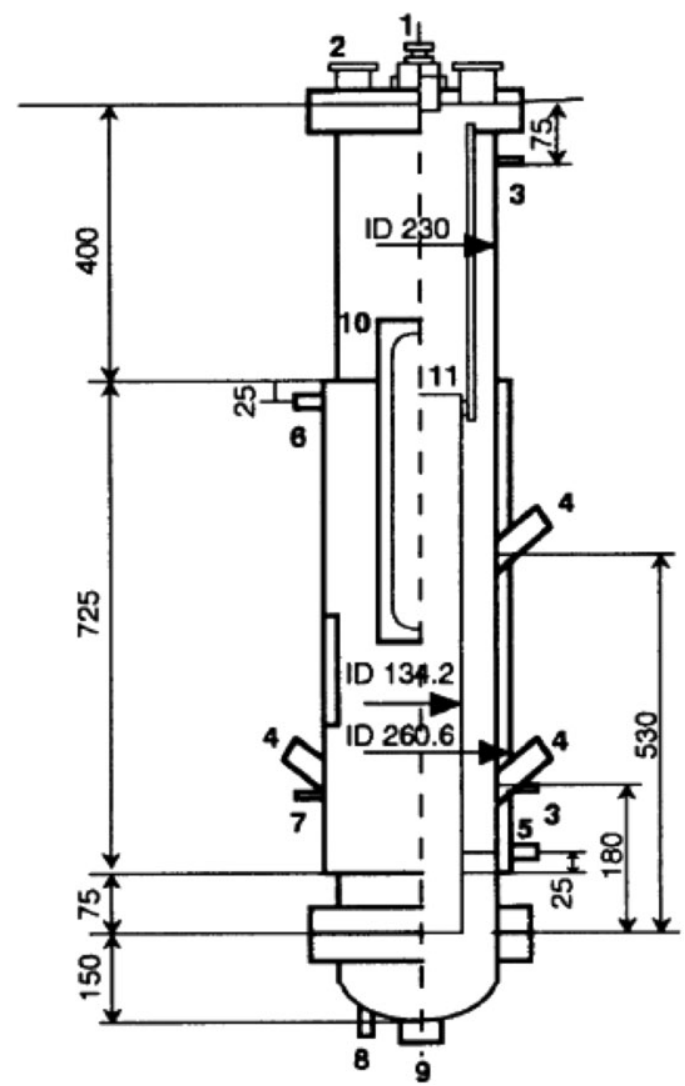

Figure 4. Schematic diagram of an airlift reactor with an internal loop (unit in mm). 1) Nozzle for inoculation, 2) gas outlet, 3) nozzles, 4) sensor nozzle, 5) inlet water temperature controller, 6) outlet water temperature controller, 7) sampling nozzle, 8) temperature sensor, 9) drain, 10) observatory window, and 11) draft tube. Obtained from Chao et al. with permission. ${ }^{[126]}$ Copyright 1997, Springer Verlag.

of the medium. This reduces the shear stresses experienced by the bacteria, thereby reducing the tendency of bacteria to mutate to non-cellulose producing strains. ${ }^{[31]}$

\subsection{Aerosol Bioreactor}

Another challenge that needs to be overcome in order to scale up the production of $\mathrm{BC}$ in bioreactors is the supply of carbon source required for bacteria to grow. It has been shown that active bacteria only exist in the top layer (up to $1 \mathrm{~mm}$ ) of the $\mathrm{BC}$ pellicles in a surface culture where the oxygen concentration is highest. ${ }^{[118,132]}$ This implies that the nutrients will have to diffuse through the $B C$ pellicles, which is the rate-limiting step in $\mathrm{BC}$ production. A rotating disk/drum reactor can be used to solve this problem. ${ }^{[133]}$ In this reactor the bacteria attached themselves onto a rotating drum/disk and the rotating motion of the drum/ disk enable the bacteria to have good contact with both air and the culture medium. One problem associated with this 


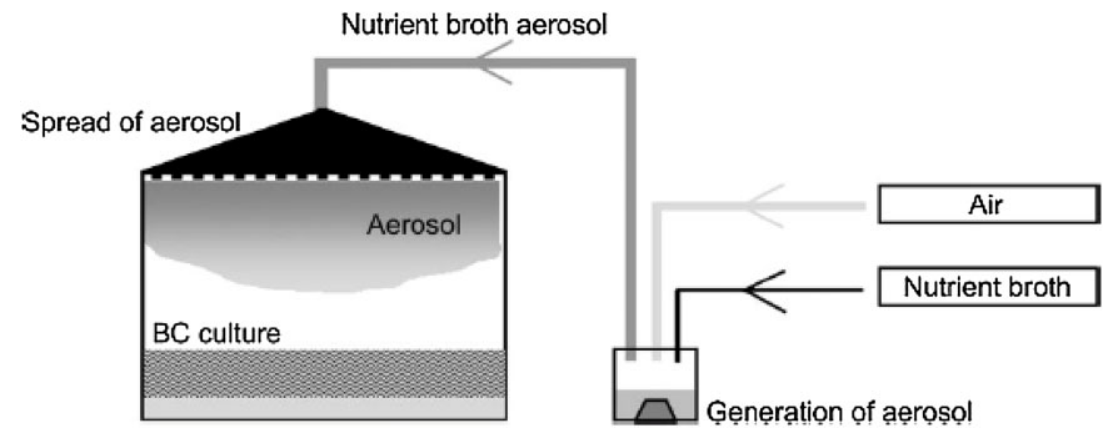

Figure 5. Schematic diagram of an aerosol reactor. The oxygen and nutrients are sprayed in the form of aerosol from the top of the reactor onto the BC pellicle. Obtained from Hornung et al. with permission. ${ }^{[134]}$ Copyright 2007, John Wiley \& Sons. beyond 8 , the production decreases. Krystynowicz et al. ${ }^{[136]}$ suggested that the increase in the number of discs could result in the agglomeration of adjacent $\mathrm{BC}$ pellicles as the distance between the discs decreased. This is hypothesized to reduce the rate of production of $\mathrm{BC}$.

\subsection{Membrane Bioreactor}

The yield of $\mathrm{BC}$ is higher in static culture compared to agitated cultures, ${ }^{[117]}$ as the shear stresses generated during the shaking motion tend to promote mutation of bacteria into non-cellulose pro-

is the production of cellulose in the culture medium, which affects the movement of the rotating drum/disk. To solve this problem, fzmb GmbH developed an aerosol reactor (see Figure 5), in which the nutrients are sprayed (in the form of aerosol) from a nozzle situated above the BC pellicle. ${ }^{[134]}$ This ensures that the bacteria, which live in the top layer of the pellicle, always receive high levels of oxygen and nutrients required for the production of $\mathrm{BC}^{8}$. The aerosol reactor can be operated for an extended period of time to maximize the biomass and $B C$ production (up to $60 \mathrm{~d}$ if no contamination occurs). $\mathrm{ABC}$ production of $9 \mathrm{~g}$ (dry mass) per day has been achieved. The maximum thickness of $B C$ pellicle produced in the reactor was approximately $7 \mathrm{~cm}$. This reactor has been scaled up by fzmb $\mathrm{GmbH}$ to produce several kilograms of BC. However, fzmb currently produces about $900 \mathrm{~kg} \mathrm{BC}$ annually, which corresponds to about $30 \mathrm{t}$ wet $B C$ material but this is produced almost entirely in static culture.

\subsection{Rotary Bioreactor}

A rotary bioreactor (Figure 6) consists of a series of circular discs mounted on a horizontal shaft. ${ }^{[135]}$ As the discs rotate, they are exposed alternatively to the culture medium and air. Kim et al. ${ }^{[119]}$ found that the optimum BC production in standard Hestrin and Shramm medium ${ }^{9}$ requires eight discs in the reactor, with a disk diameter, rotation speed, and aeration rate of $12 \mathrm{~cm}, 15 \mathrm{rpm}$, and 1.25 $\mathrm{vvm}^{10}$, respectively. $34 \%$ of the disk is submerged in the culture medium. This resulted in a BC concentration of approximately $5.5 \mathrm{gL}^{-1}$. However, the authors failed to mention why when the number of discs was increased

\footnotetext{
${ }^{8}$ The strain of bacteria used was $G$. xylinum $\mathrm{AX}_{5}$ with glucose as the carbon source.

${ }^{9}$ The strain of bacteria used was Gluconacetobacter sp. RKY 5 KCTC $10683 \mathrm{BP}$ with glucose as the carbon source.

${ }^{10} \mathrm{vvm}$ : gas volume flow rate per unit liquid volume per minute.
}

ducing strains. ${ }^{[131]}$ Therefore, it is more advantageous to produce $\mathrm{BC}$ in static cultures. In addition to this, the production rate of $B C$ per unit cross-sectional area of vessel in static culture is almost constant ${ }^{[137]}$ and hence, making the culture as shallow and as large as possible is expected to increase the $\mathrm{BC}$ production rate per unit volume. However, the size of static culture vessels in this case will be impractical for the large-scale production of BC. As a result, novel membrane bioreactors to cultivate bacteria under static conditions have explored to utilize the high surface area of membranes. Hofinger et al. ${ }^{[138]}$ used a hydrophilic polyethersulfone (PES) membrane with a pore size of $0.45 \mu \mathrm{m}$ in a membrane bioreactor to culture cellulose producing bacteria. The nutrients are passed through one side of the membrane whilst G. xylinus ${ }^{11}$ was introduced on the other side of the membrane. The nutrients needed for bacteria growth and BC production diffuse through the hydrophilic membrane. In addition to this, the membrane also serves as a separator between BC and the circulating culture medium and thus, results in a possible reduction of downstream separation cost. The medium can also be circulated on the other side of the membrane without disturbing the formation of BC. A steady BC production of $0.4 \mathrm{~g}$ (dry mass) $\mathrm{m}^{-2} \cdot \mathrm{h}^{-1}$ was reported. As aforementioned, using oxygen-enriched air increases the BC production. A similar concept was employed by Yoshino et al. ${ }^{[139]}$ Instead of air, oxygen enriched air was used and the oxygen enrichment was conducted via an oxygen permeable silicone membrane. ${ }^{12}$ Air is supplied on one side of the membrane whilst the other side is filled with culture medium inoculated with cellulose producing bacteria. A BC production rate of $\approx 0.3 \mathrm{~g}$ (dry mass) $\mathrm{m}^{-2} \mathrm{~h}^{-1}$ was reported in this case.

\footnotetext{
"The strain of bacteria used was G. xylinus strain DSM 2325 with glucose as the carbon source.

${ }^{12}$ The strain of bacteria used was Acetobacter pasteurianus AP-1SK with glucose as the carbon source.
} 

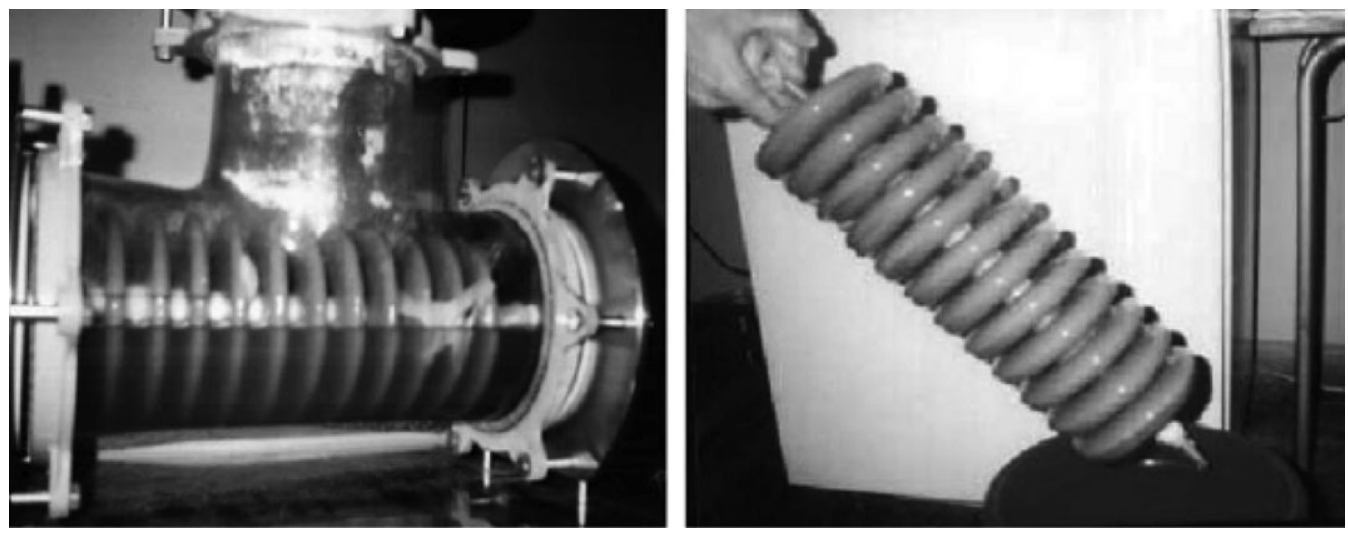

Figure 6. The biosynthesis of $B C$ in a rotary reactor (left) and the $B C$ attached to the discs after $7 \mathrm{~d}$ of culture (right). Obtained from Krystynowicz et al. with permission. ${ }^{[136]}$ Copyright 2002, Springer Verlag.

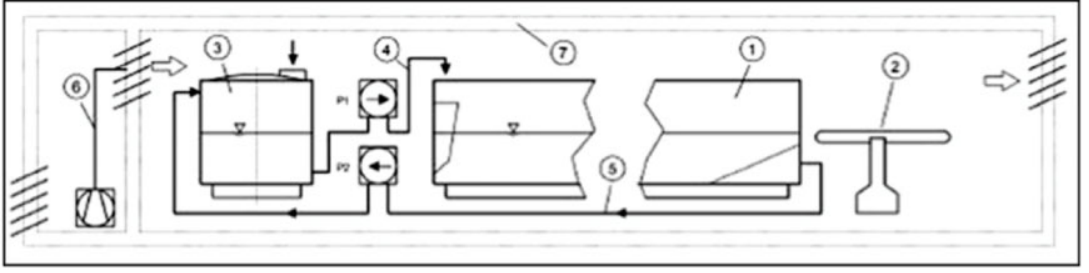

Figure 7. Schematic diagram of a horizontal lift reactor. 1) Cultivation device, 2) extractor device, 3) culture medium tank, 4) culture medium feed, 5) outlet tube for culture medium consumed, 6) air feeding, and 7) housing. Reprinted from Kralisch et al. with permission. ${ }^{[140]}$ Copyright 2010, Wiley.

\subsection{Horizontal Lift Reactor}

Most of the bioreactor systems we have discussed so far are based on batch processes. In order to extract $\mathrm{BC}$, the reactors have to be stopped. Horizontal lift reactors, get around this problem by culturing $\mathrm{BC}$ in a long tank containing culture medium and at the end of the tank, the BC pellicle is lifted and transported out of the culture medium continuously (see Figure 7 for schematic). ${ }^{[140]}$ This set up can remove the $\mathrm{BC}$ pellicle without disrupting the $3 \mathrm{D}$ network of $\mathrm{BC}$ nanofibers within the pellicle. In addition to this, the height of the BC pellicle ${ }^{13}$ can also be adjusted by increasing the length of the reactor to allow for longer growth time (at the expense of higher capital cost). It was observed that BC pellicle grow at a rate of $0.5-1.5 \mathrm{~mm}$ in thickness per day for a $20 \mathrm{~L}$ cultivation tank. However, the authors did not report the $\mathrm{BC}$ yield or production rate.

\subsection{Challenges for the Industrial-Scale Production of BC}

We have discussed, so far, numerous bioreactors that have been reported in the literature to produce $\mathrm{BC}$ on large scale.

${ }^{13}$ The strain of bacteria used was G. xylinus strain DSM 14666 with glucose as the carbon source.
However, the production of $\mathrm{BC}$ is still rather limited. One of the major challenges is the cost of $\mathrm{BC}$ production, which is directly linked to the energy consumption needed to support the growth of bacteria. The second challenge, in the authors' opinion, is the lack of a unified comparison between different reactors. Design engineers are used to working with dimensionless numbers or normalized quantities such that the efficiency between different designs can be compared. For the case of bioreactors for BC production, multiple units have been used to report the efficiency of bioreactors. These include $\mathrm{g} \mathrm{L}^{-1}, \mathrm{~g} \mathrm{~d}^{-1}$, and $\mathrm{g} \mathrm{m}^{-2} \mathrm{~h}^{-1}$. To make things worse, the bacteria species, cultivation time, and initial carbon source concentration varies between studies, which make a comparison between different technologies even more difficult. Herein, we attempt to normalize these factors into a single parameter, defined as cellulose productivity (mass of cellulose produced per unit culture medium volume and cultivation time), which allows for better comparison between different bioreactor designs (see Table 2). It can be seen from Table 2 that the aerosol bioreactor allows for the highest $\mathrm{BC}$ productivity, at a value of $0.38 \mathrm{gL}^{-1} \mathrm{~h}^{-1}$. The world production of $\mathrm{BC}$ is also highly affected by the demand for $\mathrm{BC}$ for various applications. By finding new applications for $B C$, it is more favorable for the industry to start further scaling up of BC production. The following section discusses the application of $\mathrm{BC}$ in advanced fiber composites. For non-composites related applications, namely hydrogels, ${ }^{[141,142]}$ scaffolds for tissue engineering, ${ }^{[143]}$ biomedical implants, ${ }^{[142,144]}$ wound dressing, ${ }^{[145]}$ and conductive biopolymers, ${ }^{[146]}$ the readers are referred to a recent edited book by Gama, Gatenholm, and Klemm. ${ }^{[7]}$ For the application of $\mathrm{BC}$ as Pickering emulsifiers, the readers are referred to a recent book chapter in a book edited by Oksman et al. ${ }^{[147]}$ 
Table 2. A summary of various bioreactors and their cellulose productivity.

\begin{tabular}{|c|c|c|c|c|}
\hline Reactor configuration & Bacteria species & Carbon source & $\begin{array}{l}\text { Productivity } \\
{\left[\mathrm{g} \mathrm{L}^{-1} \mathrm{~h}^{-1}\right]}\end{array}$ & Remarks \\
\hline Static culture & Aceobacter acetigenum EA-I & Hydrolyzed molasses & $0.001^{a)}$ & \\
\hline Shaken culture & Aceobacter acetigenum EA-I & Hydrolyzed molasses & $0.03^{a)}$ & \\
\hline \multirow[t]{9}{*}{ Stirred tank bioreactor } & Acetobacter xylinum subsp. & Fructose & $0.40^{\mathrm{b})}$ & $1200 \mathrm{rpm}$ \\
\hline & surcrofermentans BPR 3001A & & $0.19^{\mathrm{b})}$ & 800 rpm \\
\hline & & & $0.07^{\mathrm{b})}$ & $600 \mathrm{rpm}$ \\
\hline & A. xylinum subsp. & Molasses & $0.04^{\mathrm{a})}$ & \\
\hline & surcrofermentans BPR 2001 & & $0.07^{\mathrm{a})}$ & Heat treated \\
\hline & & & $0.07^{\mathrm{a})}$ & Acid hydrolyzed \\
\hline & & Fructose & $0.15^{\mathrm{a})}$ & \\
\hline & & & $0.26^{\mathrm{a})}$ & 0.4 wt\% agar \\
\hline & & & $0.18^{\mathrm{a})}$ & 1.0 wt\% agar \\
\hline \multirow[t]{2}{*}{ Airlift bioreactor } & A. xylinum subsp. & Fructose & $0.03^{b)}$ & Normal air \\
\hline & surcrofermentans BPR 2001 & & $0.20^{b)}$ & $\mathrm{O}_{2}$ enriched airc) \\
\hline \multirow{2}{*}{$\begin{array}{l}\text { Modified airlift bioreactor } \\
\text { (wire mesh) }\end{array}$} & A. xylinum subsp. & Glucose & $0.04^{\mathrm{b})}$ & Normal air \\
\hline & surcrofermentans BPR 2001 & & $0.11^{b)}$ & $\mathrm{O}_{2}$ enriched air ${ }^{\mathrm{d}}$ ) \\
\hline \multirow{2}{*}{$\begin{array}{l}\text { Modified airlift bioreactor } \\
\text { (spherical) }\end{array}$} & A. xylinum $\mathrm{KJ} 1$ & Glucose & $0.08^{\mathrm{a})}$ & Normal air \\
\hline & & & $0.09^{\mathrm{a})}$ & $\mathrm{O}_{2}$ enriched aire) \\
\hline Aerosol bioreactor & G. xylinum AX5 & Glucose & $0.38^{\mathrm{a})}$ & \\
\hline Rotary bioreactor & $\begin{array}{l}\text { Gluconacetobacter sp. RKY5 } \\
\text { KCTC 10683BP }\end{array}$ & Glucose & $0.06^{\mathrm{a})}$ & \\
\hline $\begin{array}{l}\text { Membrane bioreactor } \\
\text { (PES) }\end{array}$ & G. xylinus strain DSM 2325 & Glucose & $0.20^{\mathrm{a})}$ & \\
\hline \multirow{2}{*}{$\begin{array}{l}\text { Membrane bioreactor } \\
\text { (silicone) }\end{array}$} & A. pasteurianus AP-1SK & Glucose & $0.02^{\mathrm{a})}$ & Tortous airflow silicone \\
\hline & & & $0.01^{\mathrm{a})}$ & Flat sheet membrane \\
\hline
\end{tabular}

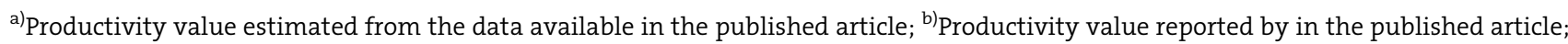

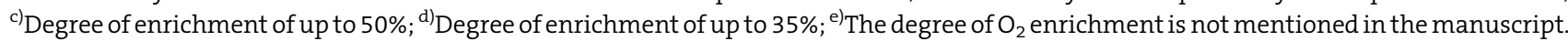

\section{Recent Advances of BC in Advanced Fiber Composites}

Crystallographically, BC possesses a cellulose I structure ${ }^{[148]}$ and X-ray diffraction shows that BC possesses a degree of crystallinity of approximately $90 \%$ (calculated using Segal's equation $\left.{ }^{[149]}\right) .{ }^{[150,151]}$ Hsieh et al. ${ }^{[152]}$ used Raman spectroscopy to determine the stiffness of a single $B C$ nanofiber. The authors estimated that a single $\mathrm{BC}$ nanofiber possesses a Young's modulus of $114 \mathrm{GPa}$. The tensile strength of a single $\mathrm{BC}$ nanofiber was estimated to be approximately $1500 \mathrm{MPa} .{ }^{[153]}$ These interesting properties of $\mathrm{BC}$ enable it to be utilized in a wide range of applications, including as nanoreinforcement for fine structures, such as polymer films, foams, fibers, and the matrices of composites. ${ }^{[16]} \mathrm{BC}$ was first used as nanoreinforcement for polymers by Gindl and Keckes. ${ }^{[154]}$ The authors reinforced cellulose acetate butyrate $(C A B)$ with $B C$. The tensile modulus and strength of the resulting nanocomposites improved by five-fold compared to neat CAB (see Table 3). Yano et al. ${ }^{[153]}$ have impregnated BC sheets with acrylic, epoxy, and phenolformaldehyde resins. Young's moduli and tensile strengths of up to $21 \mathrm{GPa}$ and $325 \mathrm{MPa}$, respectively, were measured

Table 3. The tensile properties of $B C$ reinforced $C A B$ nanocomposites. $v_{f}, E, \sigma$, and $\varepsilon$ denote fiber volume fraction of $B C$, tensile modulus, tensile strength, and strain-at-break of the material. Adapted from Gindl and Keckes. ${ }^{[154]}$

\begin{tabular}{lcccc} 
Samples & $\boldsymbol{v}_{\boldsymbol{f}}$ [\%] & $\boldsymbol{E}$ [GPa] & $\boldsymbol{\sigma}[\mathbf{M P a}]$ & $\varepsilon[\%]$ \\
\hline CAB & - & 1.2 & 25.9 & 3.5 \\
BC reinforced CAB & 10 & 3.2 & 52.6 & 3.5 \\
& 32 & 5.8 & 128.9 & 3.6 \\
& & & & \\
& & & & \\
2014, 14, 10-32 & & &
\end{tabular}



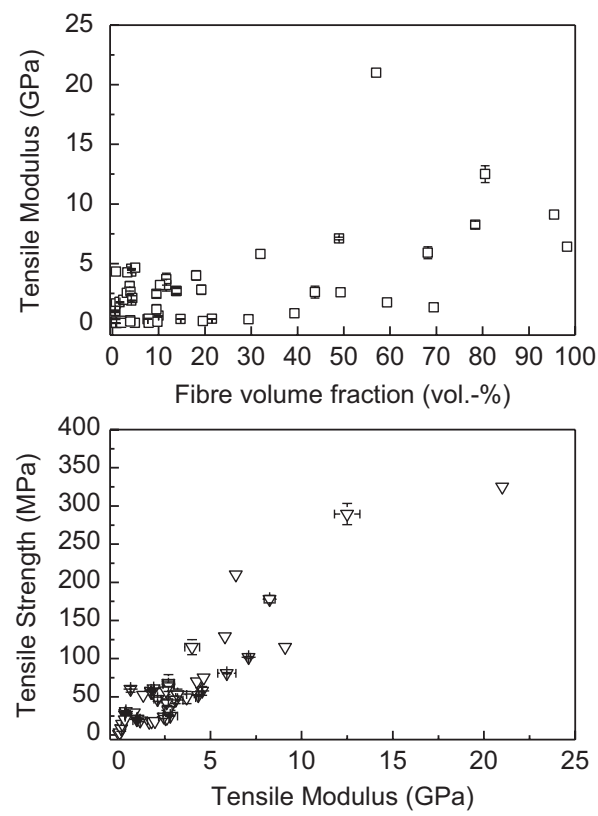

Figure 8. The tensile properties and fiber volume fraction of $B C$ reinforced nanocomposites from various authors. The polymer matrices include thermoplastic starch, PLLA, epoxidised soybean oil, epoxy, and acrylic resins. ${ }^{[17,34,153,154,156-173]}$

for the nanocomposites with BC loading fraction of $70 \mathrm{wt} \%$. This reinforcing effect comes from the stiff $\mathrm{BC}$ nanofibrils. ${ }^{[152]}$ Since then, numerous research efforts have been poured into the production of high performance BC

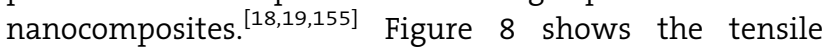
properties of BC reinforced nanocomposites obtained by various authors. ${ }^{[17,34,153,154,156-173]}$ Whilst nanocellulose can also be produced from plant fibers via grinding or high pressure homogenization processes, ${ }^{[25,26,174,175]}$ it has been shown recently that $\mathrm{BC}$ is slightly better as a nanoreinforcement for composites compared to plant-based nanocellulose $\mathrm{e}^{14}$ due to the higher crystallinity and purity of $\mathrm{BC} .{ }^{[34]}$

Numerous researchers have attempted to enhance the $B C$ fiber-polymer matrix interface by modifying the surface of BC via esterification with various anhydrides, ${ }^{[11,172]}$ carboxylic acids, ${ }^{[17,176]}$ and by polymer grafting. ${ }^{[160,177]}$ However, these results did not conclusively show that chemical modification of $\mathrm{BC}$ is the way forward to produce nanocomposites with improved mechanical performance. Whilst the BC fiber-polymer matrix interface is enhanced by chemical modifications as determined directly by measuring the contact angle between polymer melt droplets on BC fibrils, ${ }^{[17,158]}$ the tensile strength of the resulting composites did not exceed the tensile strengths of the polymers by much (typical $\approx 10-15 \%$ only). This points toward the fact that the tensile strength of single $B C$

${ }^{14}$ These nanocellulose are termed microfibrillated cellulose or nanofibrillated cellulose. nanofibers has not been fully utilized, due to the random orientation of the $\mathrm{BC}$ within a composite. More importantly, the chemically modified $\mathrm{BC}$ content in composites is rather low. Simple micromechanical modeling using Cox-Krenchel and Kelly-Tyson models showed that the lack of improvements in tensile properties could indeed be attributed to both the random orientation and low BC loading within the composites. ${ }^{[158]}$ Moreover, chemical modification of $\mathrm{BC}$ is rather laborious and solvent exchange is often needed. Starting with freeze-dried BC resulted in significant bulk modification of $\mathrm{BC}$ which affected the degree of crystallinity of the modified $B C,{ }^{[151]}$ which is not desirable when its intended to be used as nanoreinforcement for polymers.

\subsection{Nature Inspired Bacterial Cellulose Reinforced Polymer Nanocomposites}

To address this challenge, numerous researchers strive to produce BC reinforced polymer nanocomposites using a biomimetic concept. This nature inspired high performance cellulose nanocomposite concept comes from wood, ${ }^{[22]}$ which consists of cellulose that serves as the reinforcing agent for a lignin matrix. Hemicellulose in wood coats the cellulose within plant cell well and functions as a "Velcro hook," i.e., compatibilizer, between lignin and cellulose. ${ }^{[178]}$ It is this configuration that provides rigidity of woody materials. In the context of realizing this biomimetic concept in nanocomposites, BC is an ideal candidate as its production can be controlled and modified during biosynthesis to produce truly nature inspired high performance BC reinforced engineering materials. ${ }^{[179-182]}$

Water soluble polymers, such as hydroxyethyl cellulose $(\mathrm{HEC})^{[173]}$ and polyvinyl alcohol $(\mathrm{PVOH})^{[156]}$ have been introduced into the culture medium during the biosynthesis of BC. The introduction of HEC into the culture medium reduced the crystallization of $\mathrm{BC}$ fibrils, resulting in the broadening of X-ray diffraction $110,1 \overline{1} 0$, and 200 peaks corresponding to cellulose of the resulting composites. The BC reinforced nanocomposites had a BC loading $80 \mathrm{wt} \%$. When comparing the mechanical performance of conventional $\mathrm{BC}$ reinforced HEC (not prepared using by adding HEC to the culture medium) to that of biomimetic composites prepared by culturing bacteria in the presence of HEC showed that the biomimetic composites performed much better (see Table 4). The remarkable improvement in the tensile properties of biomimetic composites is due to the coating of individual BC nanofibrils with HEC induced by this preparation method. A similar trend was also observed for the nanocomposites produced by culturing bacteria in the presence of PVOH (Table 4). The tensile strength of these composites was higher than that of conventional BC reinforced $\mathrm{PVOH}$ nanocomposites produced via wet impregnation. The tensile modulus of the biomimetic $\mathrm{PVOH}$ 
Table 4. Tensile properties of nature inspire BC reinforced polymer nanocomposites. $E$ and $\sigma$ represent the tensile modulus and tensile strength, respectively. Adapted from literature. ${ }^{[80,156,173]}$

\begin{tabular}{|c|c|c|c|}
\hline Sample & $E[\mathrm{GPa}]$ & $\sigma[\mathrm{MPa}]$ & 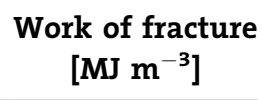 \\
\hline BC sheet & $12.5 \pm 0.3$ & $225.6 \pm 3.7$ & $10.7 \pm 0.5$ \\
\hline $\mathrm{BCHEC}^{\mathrm{a})}$ & $12.5 \pm 0.7$ & $289.4 \pm 13.87$ & $11.0 \pm 1.0$ \\
\hline $\mathrm{BC} / \mathrm{HEC}^{\mathrm{a})}$ & $8.25 \pm 0.3$ & $178.0 \pm 5.0$ & $8.1 \pm 0.4$ \\
\hline $\mathrm{BC}^{-P V A}{ }^{b)}$ & 9.1 & 110 & \\
\hline$B C-P V A^{c)}$ & 6.4 & 210 & \\
\hline$B C-P_{H B}{ }^{d)}$ & $1.10 \pm 0.11$ & $67.4 \pm 18.2$ & \\
\hline
\end{tabular}

a) $80 \mathrm{wt} \%$ BC reinforced HEC, not prepared in situ in the culture medium; ${ }^{b}$ BC reinforced PVA prepared by impregnation method. This composite consists of 98.6 wt\% BC loading; ${ }^{c} \mathrm{BC}$ reinforced PVA prepared co-culturing method. This composite consists of $96.3 \mathrm{wt} \%$ $\mathrm{BC}$ loading; ${ }^{\mathrm{d})} \mathrm{BC}$ reinforced $\mathrm{PHB}$ prepared by co-culturing method. This composite consists of $60 \mathrm{wt} \% \mathrm{BC}$ loading.

nanocomposites, however, was worse than that of conventional BC reinforced $\mathrm{PVOH}$ nanocomposites. This is attributed to the difference in $\mathrm{BC}$ loading in the composites (biomimetic BC reinforced PVOH: 96.3 wt\% BC, conventional BC reinforced PVOH: $98.6 \mathrm{wt} \% \mathrm{BC}$ ).

Non-water soluble polymers have also been used added to the culture of BC. Ruka et al. ${ }^{[80]}$ cultured BC in presence of PHB powder. However, due to the hydrophobic nature of $\mathrm{PHB}$, the mechanical performance of the resulting nanocomposites was rather disappointing. Whilst the tensile strength of the resulting BC-reinforced PHB nanocomposites exceeds that of neat $\mathrm{PHB}(\approx 21 \mathrm{MPa})$, the tensile modulus of the composites is still much lower than that of previous studies ${ }^{[156,173]}$ using water-soluble polymers that were added to the culture medium. The authors also observed that PHB is superficially attached onto the surface of the BC pellicle instead of being incorporated into the pellicle. This could explain the poor mechanical performance of the nanocomposites. In addition to this, the PHB$\mathrm{BC}$ pellicles were dried freely in air instead being of wetpressed. This will induce slack in the BC network, ${ }^{[183]}$ resulting in a poorer tensile modulus of the $\mathrm{BC}$ network, which the authors measured to be only $1.87 \pm 0.5 \mathrm{GPa}$ as opposed to $12.5 \mathrm{GPa}$ (Table 4).

\subsection{Nature Inspired Bacterial Cellulose-Reinforced, Natural Fiber-Reinforced Hierarchical Composites}

One other method of utilizing the potential of $\mathrm{BC}$ is to use it as nanoreinforcement to further reinforce the matrix of conventional fiber reinforced composites, thereby creating hierarchical composites. ${ }^{[184,185]}$ By culturing A. xylinum in the presence of natural fibers in an appropriate culture medium, BC is preferentially deposited in situ (see Figure 9) onto the surface of natural fibers. ${ }^{[186-189]}$ A layer of BC pellicles can be seen growing around the surface of the natural fibers (a weight gain of approximately 5-6 wt\% was measured). The introduction of BC onto natural fibers provides a new means of controlling the interaction between natural fibers and polymer matrices. By utilizing BC coated natural fibers as reinforcement, nanocellulose can be introduced into composites at the interface between the fibers and the matrix, leading to increased stiffness of the matrix around the natural fibers. Moreover, using BC coated fibers is an effective route of introducing an anisotropic nanoreinforcement. BC modified natural fibers have been used to produce unidirectional natural fiber reinforced $\mathrm{CAB}$ and polylactide (PLLA) model composites. ${ }^{[187,188]}$ The mechanical properties of BC coated sisal fiber reinforced polymers showed significant improvements over neat natural fiber reinforced polymers (Table 5). The tensile strength and modulus for sisal/PLLA composites improved by as much as 68 and 49\%, respectively. However, improvements were not observed for composites
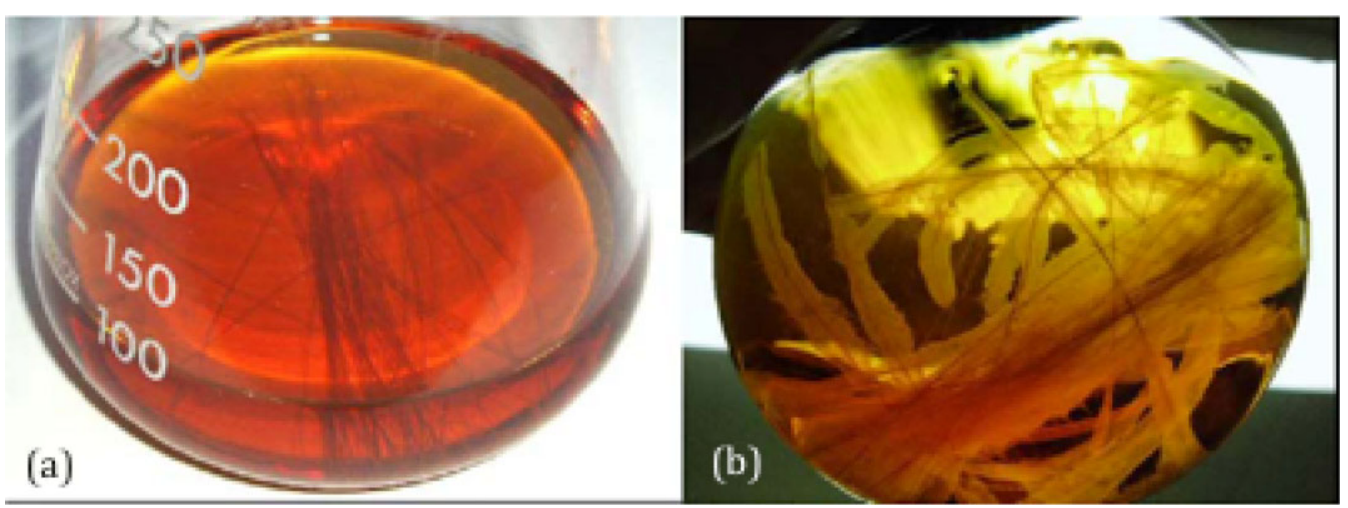

Figure 9. Images showing a) natural fibers immersed in a culture medium of $G$. xylinum before bacteria culturing b) the culture medium after 2 d. Reprinted from Pommet et al. with permission. ${ }^{[89]}$ Copyright 2008, American Chemical Society.

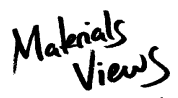

www.MaterialsViews.com 
www.mbs-journal.de

Table 5. Mechanical properties of bacterial cellulose modified hemp and sisal fibers reinforced CAB and PLLA composites. Adapted from Juntaro et al. ${ }^{[188]}$

\begin{tabular}{|c|c|c|c|c|}
\hline \multirow[b]{2}{*}{ Composites } & \multicolumn{2}{|c|}{ Neat fiber } & \multicolumn{2}{|c|}{ BC coated fiber } \\
\hline & $\sigma[\mathrm{MPa}]$ & $E[\mathrm{GPa}]$ & $\sigma[\mathrm{MPa}]$ & $E[\mathrm{GPa}]$ \\
\hline CAB/hemp ${ }^{\text {a) }}$ & $98.1 \pm 12.7$ & $8.5 \pm 1.3$ & $86.7 \pm 13.6$ & $5.8 \pm 0.5$ \\
\hline PLLA/hemp ${ }^{\text {a) }}$ & $110.5 \pm 27.2$ & $11.8 \pm 4.2$ & $104.8 \pm 9.1$ & $7.9 \pm 1.2$ \\
\hline $\mathrm{CAB} /$ sisal $^{\mathrm{a})}$ & $92.9 \pm 9.3$ & $5.5 \pm 0.5$ & $100.4 \pm 7.0$ & $8.8 \pm 1.4$ \\
\hline PLLA/sisal ${ }^{\text {a) }}$ & $78.9 \pm 14.7$ & $7.9 \pm 1.3$ & $113.8 \pm 14.0$ & $11.2 \pm 1.2$ \\
\hline CAB/hemp $p^{\text {b) }}$ & $15.8 \pm 2.2$ & $1.9 \pm 0.1$ & $13.4 \pm 1.4$ & $0.6 \pm 0.2$ \\
\hline PLLA/hemp ${ }^{\text {b) }}$ & $13.4 \pm 3.6$ & $3.2 \pm 0.2$ & $13.3 \pm 2.5$ & $2.3 \pm 0.3$ \\
\hline $\mathrm{CAB} /$ sisal $^{\mathrm{b})}$ & $10.9 \pm 1.7$ & $1.6 \pm 0.1$ & $14.4 \pm 3.7$ & $1.8 \pm 0.3$ \\
\hline PLLA/sisal ${ }^{b)}$ & $10.0 \pm 3.1$ & $2.1 \pm 0.1$ & $16.8 \pm 4.1$ & $3.1 \pm 0.2$ \\
\hline
\end{tabular}

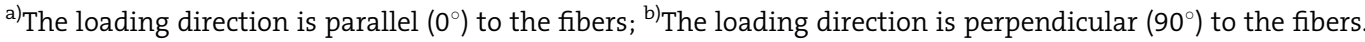

containing BC coated hemp fibers. The tensile strength and modulus decreased by as much as 15 and 69\%, respectively, for hemp/CAB composites. This is due to the fact that hemp fibers were damaged during the fermentation process reducing the fiber tensile properties of the original fibers. This was due to the properties of bast fiber (hemp) bundles, which are less cohesive than leaf fibers (sisal) bundles. ${ }^{[189]}$

Bacterial cellulose coated sisal fibers with a morphology similar to that of fibers coated with BC in a bacteria culture can also be created by slurry-dipping without the need of using a bioreactor. ${ }^{[185]}$ The sisal fibers were dipped into a suspension of $B C$ in water. The hydrophilic nature of natural fibers causes them to absorb water drawing along the $\mathrm{BC}$ within the suspension, which filters against the surface of the fibers, resulting in $\mathrm{BC}$ coated fibers. The fast drying rate of the coated fibers under vacuum resulted in the collapse of BC nanofibrils onto the surface of sisal fibers (Figure 10a). "Hairy fibers" (Figure 10b), with BC nanofibrils oriented perpendicular to the sisal surface, were produced by pressing the wet $\mathrm{BC}$ coated sisal fibers between filter papers to dry them partially. It is hypothesized that during this process, the water contained in the $\mathrm{BC}$ nanofibrils was sucked into the filter paper. The combination of capillary action with the slow drying of the coated fibers (preventing the collapse of the nanofibrils) resulted in the "hairy" fiber morphology.

The tensile properties of randomly oriented short (BC coated) sisal fiber reinforced PLLA composites were studied by Lee et al. ${ }^{[185]}$ Two different types of hierarchical composites were prepared: i) BC coated sisal reinforced PLLA and ii) BC coated sisal reinforced PLLA-BC nanocomposites. The former composites contained $\mathrm{BC}$ on the surface of sisal fibers only and the latter composites contained $\mathrm{BC}$ both on the fiber surfaces and dispersed within the PLLA matrix. From the results summarized in Table 6, it can be seen that with BC coated sisal fibers as

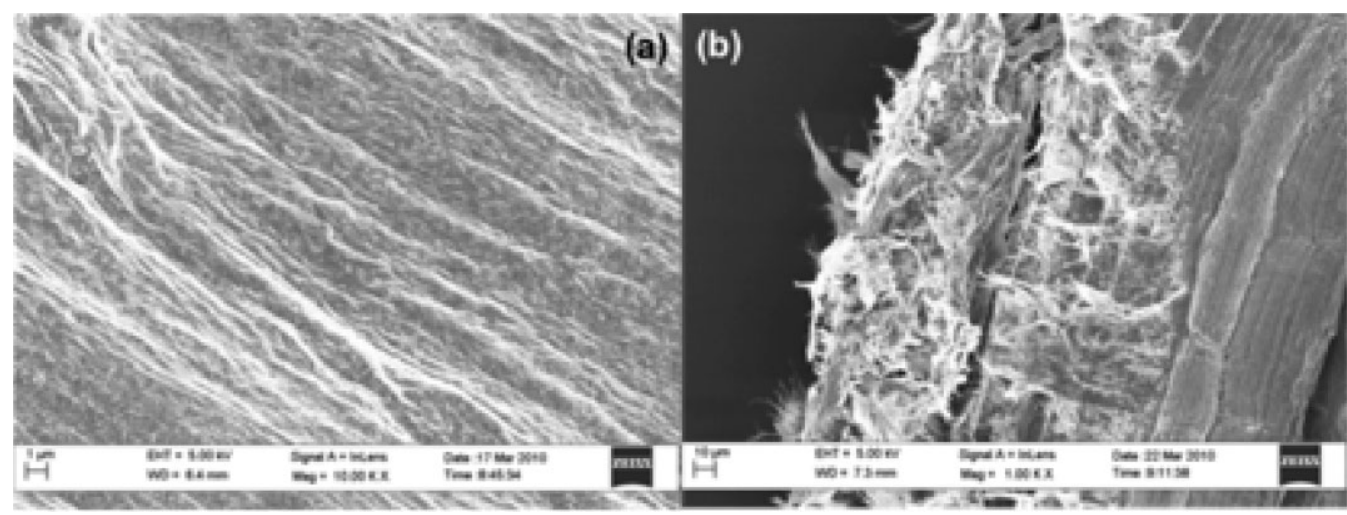

Figure 10. Scanning electron images showing a) sisal fibers coated with a dense layer of BC and b) "hairy" sisal fibers produced using a novel slurry dipping method. A dense layer of BC on sisal fibers was obtained by drying the slurry-dipped fibers under vacuum $80^{\circ} \mathrm{C}$. "Hairy" sisal fibers were obtained by partially drying the slurry-dipped fibers between filter papers, followed drying in an air oven held at $40^{\circ} \mathrm{C}$. 
Table 6. Tensile properties of (hierarchical) sisal fiber reinforced PLLA (nano)composites. PLLA-sisal, PLLA-DCNS, and PLLA-HFNS denote PLLA (nano)composites reinforced with $20 \mathrm{wt} \%$ neat sisal fibers, densely coated neat sisal fibers, and "hairy" fibers of neat sisal, respectively. PLLA-sisal-BC, PLLA-DCNS-BC and PLLA-HFNS$B C$ represent PLLA nanocomposites reinforced with $15 \mathrm{wt} \%$ neat sisal fibers, densely coated neat sisal fibers, and "hairy" fibers of neat sisal, respectively, with $5 \mathrm{wt} \% \mathrm{BC}$ dispersed in the matrix. Adapted from Lee et al. ${ }^{[185]}$

\begin{tabular}{lcc} 
Sample & $\begin{array}{c}\text { Tensile modulus } \\
\text { [GPa] }\end{array}$ & $\begin{array}{c}\text { Tensile strength } \\
\text { [MPa] }\end{array}$ \\
\hline Neat PLLA & $0.97 \pm 0.02$ & $62.6 \pm 1.0$ \\
PLLA-sisal & $1.28 \pm 0.03$ & $58.7 \pm 1.0$ \\
PLLA-DCNS & $1.35 \pm 0.03$ & $57.3 \pm 1.3$ \\
PLLS-HNSF & $1.29 \pm 0.03$ & $57.8 \pm 1.6$ \\
PLLA-Sisal-BC & $1.46 \pm 0.02$ & $60.9 \pm 1.9$ \\
PLLA-DCNS-BC & $1.63 \pm 0.04$ & $67.8 \pm 1.2$ \\
PLLA-HNSF-BC & $1.59 \pm 0.05$ & $69.2 \pm 1.2$
\end{tabular}

reinforcement, the tensile moduli for all composites increased compared to neat PLLA and sisal reinforced PLLA composites. The tensile modulus of the hierarchical composites increased further when BC was additionally dispersed in the matrix due to the stiffening of the matrix by $B C$. It was shown that PLLA can be stiffened by as much as $40 \%$ by the incorporation of $5 \mathrm{wt} \% \mathrm{BC} \cdot{ }^{[17]}$ With $\mathrm{BC}$ dispersed in the matrix and attached to the fibers, both the matrix and the fiber-matrix interface could be reinforced (or stiffened). The tensile strength of the hierarchical composites showed a slightly different trend compared to tensile modulus. A decrease in tensile strength was observed when PLLA is reinforced with (BC coated) sisal fibers alone. However, when the hierarchical composites were additionally reinforced with $B C$ dispersed in the PLLA matrix, the tensile strength improved by $11 \%$ when compared to neat PLLA and $21 \%$ when compared to BC coated sisal fiber reinforced PLLA composites without BC dispersed in the matrix. This could be due to enhanced interfacial adhesion between $B C$ coated fibers and BC reinforced PLLA matrix. With BC dispersed in the matrix, the matrix is stiffened. In general, short-fiber composites exhibit a combination of failures and fracture occurs along the weakest part of a composite. ${ }^{[190]}$ A fractographical analysis of composites failed in tension revealed that the overall fracture surface of $B C$ coated sisal fiber reinforced PLLA composites exhibited Lfiber fracture surface as the dominant mechanism (crack plane oriented parallel to fiber orientation--low fracture energy). This explained the poor tensile strengths of these composites even though the fiber-matrix interface is enhanced through mechanical interlock. Because of this mechanical interlock, the weakest region in the composite is no longer the fiber-matrix interface but the bulk polymer. However, when $\mathrm{BC}$ was additionally incorporated into the fiber reinforced PLLA composites, the overall fracture surface and hence, fracture mechanism, was modified. No significant fiber debonding or fiber pull-out was observed in the composites. This was accompanied by improved mechanical properties (both tensile strength and modulus) of hierarchical composites when compared to neat PLLA.

\subsection{Utilizing Bacterial Cellulose as Binder for Hierarchical Composites}

This slurry dipping method for creating hierarchical structures in composite materials inspired Lee et al. ${ }^{[191]}$ to create non-woven natural fiber preforms using a paper making process. Instead of dipping the sisal fibers into a water dispersion of $B C$, the dispersion of sisal fibers-BC was simply vacuum filtered, wet pressed, and dried to produce rigid and robust fiber preforms. In this preforms the natural fibers are bonded together by numerous hydrogen bonds forming between $B C$ and the natural fibers. These $B C$ bonded fiber preforms can be used for composite production. With $B C$ as the binder, a tensile strength (defined as the maximum load required to break the sample per unit width of the specimen as the cross-sectional area of the fiber mat) of $13.1 \mathrm{kN} \mathrm{m}^{-1}$ was achieved. However, the tensile strength of the neat sisal fiber preforms without BC binder could not be measured; in this case the fibers simply slide over each other. This is due to the fact that these rigid short sisal fibers are loose and held together only by friction between the fibers even after the wet pressing step to consolidate them into fiber preforms. The improved mechanical performance of BC-sisal fiber preforms can be attributed to the use of BC as the binder, which also promotes fiber-fiber stress transfer. The nanosized BC holds the otherwise loose sisal fibers together due to hornification (irreversible hydrogen bonding between the nanocellulose). ${ }^{[192]}$ The high tensile strength of the BC network, which formed in between the sisal fibers, provided the mechanical performance of the manufactured BC-sisal fiber preforms.

These natural fiber preforms were used for composite manufacturing and infused with acrylated epoxidized soybean oil (AESO) using vacuum assisted resin infusion in flexible tooling. The AESO was polymerized to produce sisal fiber reinforced hierarchical composites ${ }^{[191]}$ The fiber volume fractions of sisal-polyAESO and BC-sisal-polyAESO was $40 \mathrm{vol} \%$. When sisal fibers were used as reinforcement for polyAESO, the tensile modulus improved from $0.4 \mathrm{GPa}$ for neat polyAESO to $3.2 \mathrm{GPa}$ for $40 \mathrm{vol} \%$ sisal fiber reinforced polyAESO composites. A further improvement of the tensile modulus of the composites from 3.2 to $5.6 \mathrm{GPa}$ was achieved when $\mathrm{BC}$ was used as the binder for the natural fiber preform again due to the stiffening of polymer

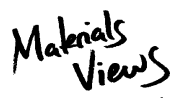

www.MaterialsViews.com

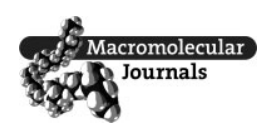


matrix when the fiber preform contained a hornified BC network.

A similar trend was observed for the tensile strength of the (hierarchical) composites. Neat polyAESO had a tensile strength of only $4.1 \mathrm{MPa}$. When neat polyAESO was reinforced with 40 vol\% sisal fibers the tensile strength increased to $18.4 \mathrm{MPa}$. A further improvement was achieved when 41 vol\% of sisal fibers and BC ( $\approx 37$ vol\% sisal and 4 vol\% BC), in form of a preform, were used as reinforcement. The tensile strength of BC-sisal-polyAESO increased by $71 \%$ and nearly $700 \%$ when compared to sisalpolyAESO and neat polyAESO, respectively. This significant improvement when $\mathrm{BC}$-sisal fiber preforms were used to create hierarchical composites can be attributed to i) the enhanced fiber-matrix interaction and ii) enhanced fiberfiber stress transfer. The use of $B C$ as binder for the fibers resulted in the formation of continuous but hornified $B C$ network, encasing sisal fibers bonding them together. It is postulated that this enhances the fiber-fiber stress transfer compared to sisal fiber only preforms, where the fibers are mostly isolated. In addition to this, it has been shown that using $B C$ as binder enhances the tensile properties of the $B C-$ sisal fiber preforms compared to sisal fiber preforms, which resulted in the improved tensile strength of the manufactured BC-sisal-polyAESO.

\section{Summary and Outlook}

Bacterial cellulose, discovered over 130 years ago by Brown, has been gaining significant attention from scientists and engineers in various research fields due to its purity, water holding capacity, and high tensile properties. In this review, we have discussed the metabolic pathways of cellulose producing bacteria; the biosynthesis of cellulose consists of four key steps involving individual enzymes, catalytic complexes, and regulatory proteins. BC is then formed between the outer and cytoplasm membranes of the cell before it is spun into protofibrils of between 2 and $4 \mathrm{~nm}$ in diameter and assembled into BC fibrils of approximately $80 \mathrm{~nm}$ in diameter.

Cellulose producing bacteria can utilize various types of carbon sources. Typically, glucose and sucrose are the most widely used carbon source for the fermentative production of BC. However, carbohydrates such as fructose, maltose, xylose, starch, mannitol, and arabitol can also be used for BC production. The addition of ethanol was found to be beneficial for the production of $B C$ as it suppresses the spontaneous mutation of cellulose producing bacteria into cellulose non-producing strains. The presence of a nitrogen source is also important for the bacteria to produce BC. Yeast extract and peptone are commonly used in Herstrin and Schramm medium. CSL can also be used as it was found to stimulate BC production.
To further enhance the yield of BC, UV-mutagenesis was used to cause mutations of the bacteria. An increase in BC of nearly $80 \%$ was observed when a ketogluconate-negative Acetobacter strain was studied. However, dgc1-disrupted mutant strains and acetan non-producing mutant strains did not provide significant increases in $\mathrm{BC}$ productivity. In the former case, the lack of improvement in $B C$ yield is hypothesized to be due to the presence of $d g c 2$ and dgc3, which complimented the function of $d g c 1$ when $d g c 1$ was disrupted in bacteria. In the latter case, the lack of acetan production reduced the viscosity of the culture medium, which then led to a decrease in $\mathrm{BC}$ production. Amorphous BC can be produced when unicellular cyanobacteria were genetically modified with by insertion of a partial cellulose synthase operon. This amorphous BC might be a suitable feedstock for biofuel production.

Various types of bioreactors have been studied or developed to scale-up BC production. These include conventional stirred tank reactors and airlift bioreactors. Novel bioreactors, such as rotary bioreactors, membrane reactors, and aerosol reactor can also be used. Currently, fzmb $\mathrm{GmbH}$ produces $30 \mathrm{t}$ per annum of wet BC mainly for cosmetic applications. In order to increase the commercial interest of BC, new application of BC should be explored. In this paper, we discussed the application of $B C$ as additional reinforcement for advanced fiber composites, as an example to reinforce fine structures. The interest in utilizing BC in composite applications stems from its high Young's modulus, estimated to be $114 \mathrm{GPa}$. This value is comparable to or higher than that of glass fibers. By culturing natural fibers in the presence of cellulose producing bacteria, BC can be coated onto the surface of natural fibers. The resulting new class of BC reinforced, natural fiber reinforced hierarchical composites showed significant improvement over conventional natural fiber reinforced composites. This improvement is attributed to the enhanced fiber-matrix interface via mechanical interlocking due to the presence of $\mathrm{BC}$. BC can also be used as a binder to bind the otherwise loose short natural fibers together to produce rigid natural fiber preforms. These preforms can be infused with green resins, such as AESO to produce hierarchal composites possesses tensile modulus and strength of $5.6 \mathrm{GPa}$ and 31.4 MPa, respectively.

However, a few challenges were encountered when scaling up the production of $B C$ to be used in various applications. One of them is the cost of production, which is directly linked to the energy consumption required to support the growth of bacteria. In addition to this, the accumulation of by-products during the growth of bacteria and the tendency of mutation to non-cellulose producing strains also slows down the progress of industrial scale production of BC. Therefore, scientists and engineers should work together to develop new strains of bacteria, which produce BC with reduced tendency of mutation and fewer 
or no by-products. Energy integration during the design phase of a $\mathrm{BC}$ production plant could also help reduce the energy consumption of $\mathrm{BC}$ production. To further drive the cost of $\mathrm{BC}$ production down, new applications of $\mathrm{BC}$ should be explored to motivate the industry to increase $B C$ production.

Acknowledgements: The authors gratefully acknowledge the financial support of the Turkey National Ministry of Education for funding GB. The authors also greatly appreciate funding provided by the University of Vienna for K.-Y. L. Furthermore, we do acknowledge the UK Engineering and Physcial Sciences Research Council (EPSRC) (EP/J013390/1) for funding.

Received: June 22, 2013; Published online: July 30, 2013; DOI: 10.1002/mabi.201300298

Keywords: bacterial cellulose; bioengineering; bioreactors; genetic modification; nanocellulose; nanocomposites

[1] A. J. Brown, J. Chem. Soc. Trans. 1886, 49, 172.

[2] J. Barsha, H. Hibbert, Can. J. Res. 1934, 10, 170.

[3] Z. Gromet, M. Schramm, S. Hestrin, Biochem. J. 1957, 67, 679.

[4] W. S. Williams, R. E. Cannon, Appl. Environ. Microbiol. 1989, 55, 2448.

[5] M. Iguchi, S. Yamanaka, A. Budhiono, J. Mater. Sci. 2000, 35, 261.

[6] W. A. Sisson, J. Phys. Chem. 1935, 40, 343.

[7] M. Gama, P. Gatenholm, D. Klemm, "Bacterial Nanocellulose: A Sophisticated Multifunctional Material”, CRC Press, Boca Raton, FL 2013.

[8] W. K. Czaja, D. J. Young, M. Kawecki, R. M. Brown, Biomacromolecules 2007, 8, 1.

[9] Y. Nishi, M. Uryu, S. Yamanaka, K. Watanabe, N. Kitamura, M. Iguchi, S. Mitsuhashi, J. Mater. Sci. 1990, 25, 2997.

[10] M. Nogi, K. Abe, K. Handa, F. Nakatsubo, S. Ifuku, H. Yano, Appl. Phys. Lett. 2006, 89, 233123.

[11] S. Ifuku, M. Nogi, A. Kentaro, H. Keishin, F. Nakatsubo, H. Yano, Biomacromolecules 2007, 8, 1937.

[12] J. J. Blaker, K. Y. Lee, X. X. Li, A. Menner, A. Bismarck, Green Chem. 2009, 11, 1321.

[13] I. Kalashnikova, H. Bizot, B. Cathala, I. Capron, Langmuir 2011, 27, 7471.

[14] I. Kalashnikova, H. Bizot, B. Cathala, I. Capron, Biomacromolecules 2012, 13, 267.

[15] H. Ougiya, K. Watanabe, Y. Morinaga, F. Yoshinaga, Biosci. Biotechnol. Biochem. 1997, 61, 1541.

[16] K. Y. Lee, L. L. C. Wong, J. J. Blaker, J. M. Hodgkinson, A. Bismarck, Green Chem. 2011, 13, 3117.

[17] K.-Y. Lee, J. J. Blaker, A. Bismarck, Compos. Sci. Technol. 2009, 69, 2724.

[18] S. J. Eichhorn, A. Dufresne, M. Aranguren, N. E. Marcovich, J. R. Capadona, S. J. Rowan, C. Weder, W. Thielemans, M. Roman, S. Renneckar, W. Gindl, S. Veigel, J. Keckes, H. Yano, K. Abe, M. Nogi, A. N. Nakagaito, A. Mangalam, J. Simonsen, A. S. Benight, A. Bismarck, L. A. Berglund, T. Peijs, J. Mater. Sci. 2010, 45, 1.
[19] J. J. Blaker, K. Y. Lee, A. Bismarck, J. Biobased Mater. Bioenergy 2011, 5, 1.

[20] W. Czaja, A. Krystynowicz, S. Bielecki, R. M. Brown, Biomaterials 2006, 27, 145.

[21] E. J. Vandamme, S. De Baets, A. Vanbaelen, K. Joris, P. De Wulf, Polym. Degrad. Stabil. 1998, 59, 93.

[22] A. Bismarck, S. Mishra, T. Lampke, "Plant Fibers as Reinforcement for Green Composites," in: Natural Fibers, Biopolymers and Biocomposites, 1st edition, A. K. Mohanty, M. Misra, L. T. Drzal, Eds., CRC Press, Boca Raton, FL 2005, p. 37.

[23] J. R. Colvin, J. Polym. Sci. 1961, 49, 473.

[24] R. Jonas, L. F. Farah, Polym. Degrad. Stabil. 1998, 59, 101.

[25] A. F. Turbak, F. W. Snyder, K. R. Sandberg, J. Appl. Polym. Sci. : Appl. Polym. Sympos. 1983, 37, 459.

[26] F. W. Herrick, R. L. Casebier, J. K. Hamilton, K. R. Sandberg, "Microfibrillated Cellulose: Morphology and Accessibility". in: Proceedings of 9th Cellulose Conference, A. Sarko, (Ed., Wiley, New York 1983, p. 37/797.

[27] S. Iwamoto, A. N. Nakagaito, H. Yano, M. Nogi, Appl. Phys. AMater. Sci. Process. 2005, 81, 1109.

[28] K. Wuhrmann, A. Heuberger, K. Mühlethaler, Experientia 1946, 2, 105.

[29] A. Frey-Wyssling, Experientia 1953, 9, 181.

[30] F. J. Kolpak, J. Blackwell, Textile Res. J. 1975, 45, 568.

[31] S. Bielecki, A. Krystynowicz, M. Turkiewicz, H. Kalinowska, Bacterial Cellulose, WILEY-VCH Verlag GMBH \& Co. KGaA, Weinheim, Germany 2005, p. 31.

[32] US 4742164 (1988) Ajinomoto Co, Inc, invs.M. Iguchi, S. Mitsuhashi, K. Ichimura, Y. Nishi, S. Yamanaka, M. Uryu, K. Watanabe.

[33] A. Budhiono, B. Rosidi, H. Taher, M. Iguchi, Carbohydr. Polym. 1999, 40, 137

[34] K. Y. Lee, T. Tammelin, K. Schulfter, H. Kiiskinen, J. Samela, A. Bismarck, ACS Appl. Mater. Interfaces 2012, 4, 4078.

[35] P. R. Chawla, I. B. Bajaj, S. A. Survase, R. S. Singhal, Food Technol. Biotechnol. 2009, 47, 107.

[36] M. Shoda, Y. Sugano, Biotechnol. Bioprocess Eng. 2005, 10, 1.

[37] D. Klemm, B. Heublein, H. P. Fink, A. Bohn, Angew. Chem. Int. Ed. 2005, 44, 3358.

[38] A. G. Matthysse, J. Bacteriol. 1983, 154, 906.

[39] M. H. Deinema, L. P. Zevenhui, Archiv Fur Mikrobiologie 1971, $78,42$.

[40] R. E. Cannon, S. M. Anderson, Crit. Rev. Microbiol. 1991, 17, 435.

[41] N. Sunagawa, K. Tajima, M. Hosoda, S. Kawano, R. Kose, Y. Satoh, M. Yao, T. Dairi, Cellulose 2012, 19, 1989.

[42] B. Garcia, C. Latasa, C. Solano, F. G. Portillo, C. Gamazo, I. Lasa, Mol. Microbiol. 2004, 54, 264.

[43] S. Fiedler, M. Fussel, K. Sattler, Zentralblatt Fur Mikrobiologie 1989, 144, 473.

[44] J. Y. Jung, J. K. Park, H. N. Chang, Enzyme Microb. Technol. 2005, 37, 347

[45] P. Ross, R. Mayer, M. Benziman, Microbiol. Rev. 1991, 55, 35.

[46] R. M. Brown, Pure Appl. Chem. 1999, 71, 767.

[47] R. M. Brown, J. Macromol. Sci. Pure Appl. Chem. 1996, A33, 1345.

[48] T. Kondo, E. Togawa, R. M. Brown, Biomacromolecules 2001, 2, 1324.

[49] U. Romling, Res. Microbiol. 2002, 153, 205.

[50] D. P. Delmer, Y. Amor, Plant Cell 1995, 7, 987.

[51] D. Klemm, D. Schumann, U. Udhardt, S. Marsch, Prog. Polym. Sci. 2001, 26, 1561.

[52] R. M. Brown, J. Polym. Sci. Pol. Chem. 2004, 42, 487. 
[53] I. M. Saxena, R. Malcolm Brown, Jr., "Biosynthesis of Bacterial Cellulose". in: Bacterial Nanocellulose: A Sophisticated Multifunctional Material, M. Gama, P. Gatenholm, D. Klemm, Eds., CRC Press, Boca Raton, FL 2013, p. 1.

[54] S. Valla, D. H. Coucheron, E. Fjaervik, J. Kjosbakken, H. Weinhouse, P. Ross, D. Amikam, M. Benziman, Mol. Gen. Genetics 1989, 217, 26.

[55] P. Ross, R. Mayer, H. Weinhouse, D. Amikam, Y. Huggirat, M. Benziman, E. Devroom, A. Fidder, P. Depaus, L. Sliedregt, G. A. Vandermarel, J. H. Vanboom, J. Biol. Chem. 1990, 265, 18933.

[56] N. Tonouchi, T. Tsuchida, F. Yoshinaga, T. Beppu, S. Horinouchi, Biosci. Biotechnol. Biochem. 1996, 60, 1377.

[57] H. Weinhouse, S. Sapir, D. Amikam, Y. Shilo, G. Volman, P. Ohana, M. Benziman, FEBS Lett. 1997, 416, 207.

[58] R. M. Brown, I. M. Saxena, Plant Physiol. Biochem. 2000, 38, 57.

[59] J. De Ley, M. Gillis, J. Swings, "Family VI. Acetobacteraceae." in: Bergey's Manual of Systematic Bacteriology, N. R. Krieg, J. G. Hold, Eds., Williams \& Wilkins, Baltimore, MD 1984, p. 267.

[60] N. I. Deiannino, R. O. Couso, M. A. Dankert, J. Gen. Microbiol. 1988, 134, 1731.

[61] H. C. Wong, A. L. Fear, R. D. Calhoon, G. H. Eichinger, R. Mayer, D. Amikam, M. Benziman, D. H. Gelfand, J. H. Meade, A. W. Emerick, R. Bruner, A. Benbassat, R. Tal, Proc. Natl. Acad. Sci. U.S.A. 1990, 87, 8130.

[62] I. M. Saxena, K. Kudlicka, K. Okuda, R. M. Brown, J. Bacteriol. 1994, 176, 5735

[63] S. Kawano, K. Tajima, Y. Uemori, H. Yamashita, T. Erata, M. Munekata, M. Takai, DNA Res. 2002, 9, 149.

[64] Y. Umeda, A. Hirano, M. Ishibashi, H. Akiyama, T. Onizuka, M. Ikeuchi, Y. Inoue, DNA Res. 1999, 6, 109.

[65] S.-O. Hu, Y.-G. Gao, K. Tajima, N. Sunagawa, Y. Zhou, S. Kawano, T. Fujiwara, T. Yoda, D. Shimura, Y. Satoh, M. Munekata, I. Tanaka, M. Yao, Proc. Natl. Acad. Sci. U.S.A. 2010, 107, 17957.

[66] R. Standal, T. G. Iversen, D. H. Coucheron, E. Fjaervik, J. M. Blatny, S. Valla, J. Bacteriol. 1994, 176, 665.

[67] H. M. Koo, S. H. Song, Y. R. Pyun, Y. S. Kim, Biosci. Biotechnol. Biochem. 1998, 62, 2257.

[68] N. Tonouchi, N. Thara, T. Tsuchida, F. Yoshinaga, T. Beppu, S. Horinouchi, Biosci. Biotechnol. Biochem. 1995, 59, 805.

[69] S. Kawano, K. Tajima, H. Kono, T. Erata, M. Munekata, M. Taka, J. Biosci. Bioeng. 2002, 94, 275.

[70] N. Sunagawa, T. Fujiwara, T. Yoda, S. Kawano, Y. Satoh, M. Yao, K. Tajima, T. Dairi, J. Biosci. Bioeng. 2013, 115, 607.

[71] D. H. Coucheron, J. Bacteriol. 1991, 173, 5723.

[72] S. Kawano, K. Tajima, H. Kono, Y. Numata, H. Yamashita, Y. Satoh, M. Munekata, J. Biosci. Bioeng. 2008, 106, 88.

[73] S. Masaoka, T. Ohe, N. Sakota, J. Ferment. Bioeng. 1993, 75, 18.

[74] K. Muehlethaler, Die Makromoleculare Chemie 1948, 2, 132.

[75] M. Ishihara, M. Matsunaga, N. Hayashi, V. Tisler, Enzyme Microb. Technol. 2002, 31, 986.

[76] H. J. Son, H. G. Kim, K. K. Kim, H. S. Kim, Y. G. Kim, S. J. Lee, Bioresour. Technol. 2003, 86, 215.

[77] S. Keshk, K. Sameshima, Afr. J. Biotechnol. 2005, 4, 478.

[78] D. Mikkelsen, B. M. Flanagan, G. A. Dykes, M. J. Gidley, J. Appl. Microbiol. 2009, 107, 576.

[79] H.-I. Jung, J.-H. Jeong, O. M. Lee, G.-T. Park, K.-K. Kim, H.-C. Park, S.-M. Lee, Y.-G. Kim, H.-J. Son, Bioresour. Technol. 2010, 101, 3602.

[80] D. R. Ruka, G. P. Simon, K. M. Dean, Carbohydr. Polym. 2012, 89, 613.
[81] G. Z. Pourramezan, A. M. Roayaei, O. R. Qezelbash, Biotechnology 2009, 8, 150.

[82] E. P. Coban, H. Biyik, Afr. J. Biotechnol. 2011, 10, 5346.

[83] M. Matsuoka, T. Tsuchida, K. Matsushita, O. Adachi, F. Yoshinaga, Biosci. Biotechnol. Biochem. 1996, 60, 575.

[84] S. Hestrin, M. Schramm, Biochem. J. 1954, 58, 345.

[85] S. Yamanaka, K. Watanabe, N. Kitamura, M. Iguchi, S. Mitsuhashi, Y. Nishi, M. Uryu, J. Mater. Sci. 1989, 24, 3141.

[86] L. L. Zhou, D. P. Sun, L. Y. Hu, Y. W. Li, J. Z. Yang, J. Ind. Microbiol. Biotechnol. 2007, 34, 483.

[87] H. Toyosaki, T. Naritomi, A. Seto, M. Matsuoka, T. Tsuchida, F. Yoshinaga, Biosci. Biotechnol. Biochem. 1995, 59, 1498.

[88] S. Bae, M. Shoda, Biotechnol. Bioeng. 2005, 90, 20.

[89] S. Bae, M. Shoda, Biotechnol. Prog. 2004, 20, 1366.

[90] J. K. Park, J. Y. Jung, Y. H. Park, Biotechnol. Lett. 2003, 25, 2055.

[91] H. J. Son, M. S. Heo, Y. G. Kim, S. J. Lee, Biotechnol. Appl. Biochem. 2001, 33, 1.

[92] US 4863565 (1989) Weyerhaeuser Company, invs.D. C. Johnson, A. N. Neogi.

[93] K. V. Ramana, A. Tomar, L. Singh, World J. Microbiol. Biotechnol. 2000, 16, 245.

[94] A. Ishkawa, M. Matsuoka, T. Tsuchida, F. Yoshinaga, Biosci. Biotechnol. Biochem. 1995, 59, 2259.

[95] S. Premjet, D. Premjet, Y. Ohtani, Sen-I Gakkaishi 2007, 63, 193.

[96] S. Keshk, T. M. A. Razek, K. Sameshima, Afr. J. Biotechnol. 2006, 5, 1519.

[97] S. H. Moon, J. M. Park, H. Y. Chun, S. J. Kim, Biotechnol. Bioprocess Eng. 2006, 11, 26.

[98] F. D. E. Goelzer, P. C. S. Faria-Tischer, J. C. Vitorino, M. R. Sierakowski, C. A. Tischer, Mater. Sci. Eng. C 2009, 29, 546.

[99] X. B. Zeng, J. Liu, J. Chen, O. J. Wang, Z. T. Li, H. Y. Wang, J. Ind. Microbiol. Biotechnol. 2011, 38, 1993.

[100] N. Noro, Y. Sugano, M. Shoda, Appl. Microbiol. Biotechnol. 2004, 64, 199.

[101] A. Hirai, M. Tsuji, F. Horii, Cellulose 1997, 4, 239.

[102] A. Shirai, M. Takahashi, H. Kaneko, S. I. Nishimura, M. Ogawa, N. Nishi, S. Tokura, Int. J. Biol. Macromol. 1994, 16, 297.

[103] S. Tantratian, P. Tammarate, W. Krusong, P. Bhattarakosol, A. APhunsri, J. Sci. Res. Chula Univ. 2005, 30, 179.

[104] J. W. Hwang, Y. K. Yang, J. K. Hwang, Y. R. Pyun, Y. S. Kim, J. Biosci. Bioeng. 1999, 88, 183.

[105] P. DeWulf, K. Joris, E. J. Vandamme, J. Chem. Technol. Biotechnol. 1996, 67, 376.

[106] S. O. Bae, Y. Sugano, K. Ohi, M. Shoda, Appl. Microbiol. Biotechnol. 2004, 65, 315.

[107] R. Tal, H. C. Wong, R. Calhoon, D. Gelfand, A. L. Fear, G. Volman, R. Mayer, P. Ross, D. Amikam, H. Weinhouse, A. Cohen, S. Sapir, P. Ohana, M. Benziman, J. Bacteriol. 1998, 180,4416

[108] R. O. Couso, L. Ielpi, M. A. Dankert, J. Gen. Microbiol. 1987, 133,2123

[109] T. Ishida, Y. Sugano, T. Nakai, M. Shoda, Biosci. Biotechnol. Biochem. 2002, 66, 1677.

[110] G. Helenius, H. Backdahl, A. Bodin, U. Nannmark, P. Gatenholm, B. Risberg, J. Biomed. Mater. Res. Part A 2006, $76 A, 431$.

[111] V. Yadav, B. J. Paniliatis, H. Shi, K. Lee, P. Cebe, D. L. Kaplan, Appl. Environ. Microbiol. 2010, 76, 6257.

[112] J. W. Lee, F. Deng, W. G. Yeomans, A. L. Allen, R. A. Gross, D. L. Kaplan, Appl. Environ. Microbiol. 2001, 67, 3970.

[113] T. Nakai, Y. Nishiyama, S. Kuga, Y. Sugano, M. Shoda, Biochem. Biophys. Res. Commun. 2002, 295, 458. 
[114] S. Kawano, Y. Yasutake, K. Tajima, Y. Satoh, M. Yao, I. Tanaka, M. Munekata, Acta Crystallogr. 2005, 61, 252.

[115] D. R. Nobles, R. M. Brown, Cellulose 2008, 15, 691.

[116] T. Shigematsu, K. Takamine, M. Kitazato, T. Morita, T. Naritomi, S. Morimura, K. Kida, J. Biosci. Bioeng. 2005, 99, 415.

[117] W. F. Dudman, J. Gen. Microbiol. 1960, 21, 327.

[118] M. Hornung, M. Ludwig, A. M. Gerrard, H. P. Schmauder, Eng. Life Sci. 2006, 6, 537.

[119] Y. J. Kim, J. N. Kim, Y. J. Wee, D. H. Park, H. W. Ryu, Appl. Biochem. Biotechnol. 2007, 137, 529.

[120] T. Kouda, H. Yano, F. Yoshinaga, M. Kaminoyama, M. Kamiwano, J. Ferment. Bioeng. 1996, 82, 382.

[121] T. Kouda, H. Yano, F. Yoshinaga, J. Ferment. Bioeng. 1997, 83, 371.

[122] S. O. Bae, M. Shoda, Appl. Microbiol. Biotechnol. 2005, 67, 45.

[123] S. Bae, Y. Sugano, M. Shoda, J. Biosci. Bioeng. 2004, 97, 33.

[124] M. Y. Chisti, M. Mooyoung, Chem. Eng. Commun. 1987, 60, 195.

[125] M. Y. Chisti, M. Mooyoung, Biotechnol. Bioeng. 1988, 31, 487.

[126] Y. P. Chao, Y. Sugano, T. Kouda, F. Yoshinaga, M. Shoda, Biotechnol. Techniques 1997, 11, 829.

[127] Y. Chao, Y. Sugano, M. Shoda, Appl. Microbiol. Biotechnol. 2001, 55, 673.

[128] Y. P. Chao, T. Ishida, Y. Sugano, M. Shoda, Biotechnol. Bioeng. 2000, 68, 345

[129] H. P. Cheng, P. M. Wang, J. W. Chen, W. T. Wu, Biotechnol. Appl. Biochem. 2002, 35, 125.

[130] C. N. Choi, H. J. Song, M. J. Kim, M. H. Chang, S. J. Kim, Korean J. Chem. Eng. 2009, 26, 136.

[131] S. Valla, J. Kjosbakken, J. Gen. Microbiol. 1982, 128, 1401.

[132] M. Hornung, M. Ludwig, A. M. Gerrard, H. P. Schmauder, Eng. Life Sci. 2006, 6, 546.

[133] EP850314A; WO9705271A; WO9705271A1; AU9666837A; EP850314A1; JP10510437W; US5955326A; JP3184537B2; EP850314B1; DE69633629E; CA2228450C; DE69633629T2 (1996) Rensselaer Polytech Inst; Rensselaer Polytechnic Inst, invs.H. R. Bungay, G. C. Serafica, H. R. I. Bungay, C. Serafica.

[134] M. Hornung, M. Ludwig, H. P. Schmauder, Eng. Life Sci. 2007, 7, 35.

[135] J. L. Wang, Bioresour. Technol. 2000, 75, 245.

[136] A. Krystynowicz, W. Czaja, A. Wiktorowska-Jezierska, M. Goncalves-Miskiewicz, M. Turkiewicz, S. Bielecki, J. Ind. Microbiol. Biotechnol. 2002, 29, 189.

[137] A. Okiyama, H. Shirae, H. Kano, S. Yamanaka, Food Hydrocolloids 1992, 6, 471.

[138] M. Hofinger, G. Bertholdt, D. Weuster-Botz, Biotechnol. Bioeng. 2011, 108, 2237.

[139] T. Yoshino, T. Asakura, K. Toda, J. Ferment. Bioeng. 1996, $81,32$.

[140] D. Kralisch, N. Hessler, D. Klemm, R. Erdmann, W. Schmidt, Biotechnol. Bioeng. 2010, 105, 740.

[141] A. Haque, T. Kurokawa, J. P. Gong, "Tough Bacterial Nanocellulose Hydrogels Based on the Double-Network Technique," in: Bacterial Nanocellulose: A Sophisticated Multifunctional Material, M. Gama, P. Gatenholm, D. Klemm, Eds., CRC Press, Boca Raton, FL 2013, p. 73.

[142] D. Klemm, H. Ahrem, F. Kramer, W. Fried, J. Wippermann, R. W. Kinne, "Bacterial Nanocellulose Hydrogels Designed as Bioartificial Medical Implants," in: Bacterial Nanocellulose: A Sophisticated Multifunctional Material, M. Gama, P. Gatenholm, D. Klemm, Eds., CRC Press, Boca Raton, FL 2013, p. 175.
[143] P. Gatenholm, K. Hoglund, S. Johannesson, M. Puchades, C. Brackmann, A. Enejder, L. Olsson, "Effect of Cultivation Conditions on the Structure and Morphological Properties of BNC Biomaterials with a Focus on Vascular Grafts," in: Bacterial Nanocellulose: A Sophisticated Multifunctional Material, M. Gama, P. Gatenholm, Klemm, Eds., CRC Press, Boca Raton, FL 2013, p. 19.

[144] P. Gatenholm, J. Berry, A. Rojas, M. B. Sano, R. V. Davalos, K. Johnson, L. O'Rourke, "Bacterial nanocellulose biomaterials with controlled architecture for tisse engineering scaffolds and customizable implants". in: Bacterial Nanocellulose: A sophisticated multifunctional material, M. Gama, P. Gatenholm, D. Klemm, Eds., CRC Press, Boca Raton, FL 2013, p. 197.

[145] S. Bielecki, H. Kalinowska, A. Krystynowicz, K. Kubiak, M. Kolodziejczyk, M. de Groeve, "Wound dressings and cosmetic materials from bacterial nanocellulose". in: Bacterial Nanocellulose: A sophisticated multifunctional material, M. Gama, P. Gatenholm, D. Klemm, Eds., CRC Press, Boca Raton, FL 2013, p. 157.

[146] F. Dourado, D. Muller, C. Nunes, C. Roambo, G. Mariz de Oliveira Barra, "Bacterial Nanocellulose as a Structured Platform for Conductive Biopolymers," in: Bacterial Nanocellulose: A Sophisticated Multifunctional Material, M. Gama, P. Gatenholm, D. Klemm, Eds., CRC Press, Boca Raton, FL 2013, p. 239.

[147] K.-Y. Lee, A. Bismarck, "Colloidal and Nanocellulose Stabilised Emulsions," in: Handbook of Green Materials: Processing Technologies, Properties and Applications, K. Oksman, A. P. Mathew, M. Sain, A. Bismarck, P. Ovintus, O. J. Rojas, R. Narayan, Eds., World Scientific Publishing Ltd, Singapore in press, 2013.

[148] D. L. Vanderhart, R. H. Atalla, Macromolecules 1984, 17, 1465.

[149] L. Segal, J. J. Creely, A. E. Martin-Jr, C. M. Conrad, Text. Res. J. 1959, 29, 786.

[150] K.-Y. Lee, F. Quero, J. J. Blaker, C. A. S. Hill, S. J. Eichhorn, A. Bismarck, Cellulose 2011, 18, 595.

[151] K. Y. Lee, A. Bismarck, Cellulose 2012, 19, 891.

[152] Y. C. Hsieh, H. Yano, M. Nogi, S. J. Eichhorn, Cellulose 2008, 15, 507.

[153] H. Yano, J. Sugiyama, A. N. Nakagaito, M. Nogi, T. Matsuura, M. Hikita, K. Handa, Adv. Mater. 2005, 17, 153.

[154] W. Gindl, J. Keckes, Compos. Sci. Technol. 2004, 64, 2407.

[155] I. Siro, D. Plackett, Cellulose 2010, 17, 459.

[156] S. Gea, E. Bilotti, C. T. Reynolds, N. Soykeabkeaw, T. Peijs, Mater. Lett. 2010, 64, 901.

[157] J. S. Stevanic, C. Joly, K. S. Mikkonen, K. Pirkkalainen, R. Serimaa, C. Remond, G. Toriz, P. Gatenholm, M. Tenkanen, L. Salmen, J. Appl. Polym. Sci. 2011, 122, 1030.

[158] K.-Y. Lee, M. Tang, C. K. Williams, A. Bismarck, Compos. Sci. Technol. 2012, 72, 1646.

[159] L. Hu, Y. Wan, F. He, H. L. Luo, H. Liang, X. Li, J. Wang, Mater. Lett. 2009, 63, 1952.

[160] F. Quero, S. J. Eichhorn, M. Nogi, H. Yano, K. Y. Lee, A. Bismarck, J. Polym. Environ. 2012, 20, 916.

[161] Y. Z. Wan, H. Luo, F. He, H. Liang, Y. Huang, X. L. Li, Compos. Sci. Technol. 2009, 69, 1212.

[162] I. M. G. Martins, S. P. Magina, L. Oliveira, C. S. R. Freire, A. J. D. Silvestre, C. P. Neto, A. Gandini, Compos. Sci. Technol. 2009, 69, 2163.

[163] E. Trovatti, L. Oliveira, C. S. R. Freire, A. J. D. Silvestre, C. P. Neto, J. Pinto, A. Gandini, Compos. Sci. Technol. 2010, 70, 1148.

[164] C. Zhijiang, Y. Guang, Mater. Lett. 2011, 65, 182. 
[165] N. Soykeabkaew, N. Laosat, A. Ngaokla, N. Yodsuwan, T. Tunkasiri, Compos. Sci. Technol. 2012, 72, 845.

[166] A. Retegi, I. Algar, L. Martin, F. Altuna, P. Stefani, R. Zuluaga, P. Ganan, I. Mondragon, Cellulose 2012, 19, 103.

[167] E. Ten, J. Turtle, D. Bahr, L. Jiang, M. Wolcott, Polymer 2010, 51, 2652.

[168] R. J. Gu, B. V. Kokta, K. Frankenfeld, K. Schlufter, BioResources 2010, 5, 2195.

[169] F. Quero, M. Nogi, H. Yano, K. Abdulsalami, S. M. Holmes, B. H. Sakakini, S. J. Eichhorn, ACS Appl. Mater. Interfaces 2010, 2, 321.

[170] Z. O. Li, X. D. Zhou, C. H. Pei, Polym. -Plast. Technol. Eng. 2010, 49, 141.

[171] K. Peng, B. Wang, S. Chen, C. Zhong, H. Wang, J. Macromol. Sci Part B Phys. 2011, 50, 1921.

[172] L. C. Tome, R. J. B. Pinto, E. Trovatti, C. S. R. Freire, A. J. D. Silvestre, C. P. Neto, A. Gandini, Green Chem. 2011, 13, 419.

[173] O. Zhou, E. Malm, H. Nilsson, P. T. Larsson, T. Iversen, L. A. Berglund, V. Bulone, Soft Matter 2009, 5, 4124.

[174] N. Lavoine, I. Desloges, A. Dufresne, J. Bras, Carbohydr. Polym. 2012, 90, 735.

[175] D. Klemm, F. Kramer, S. Moritz, T. Lindstrom, M. Ankerfors, D. Gray, A. Dorris, Angew. Chem. -Int. Ed. 2011, 50, 5438.

[176] S. Berlioz, S. Molina-Boisseau, Y. Nishiyama, L. Heux, Biomacromolecules 2009, 10, 2144.

[177] P. S. S. Lacerda, A. M. M. V. Barros-Timmons, C. S. R. Freire, A. J. D. Silvestre, C. P. Neto, Biomacromolecules 2013.

[178] D. Kretschmann, Nat. Mater. 2003, 2, 775.
[179] M. Seifert, S. Hesse, V. Kabrelian, D. Klemm, J. Polym. Sci. Polym. Chem. 2004, 42, 463.

[180] C. Tokoh, K. Takabe, J. Sugiyama, M. Fujita, Cellulose 2002, 9 , 65.

[181] H. Yamamoto, F. Horii, A. Hirai, Cellulose 1996, 3, 229.

[182] C. H. Haigler, A. R. White, R. M. Brown, K. M. Cooper, J. Cell Biol. 1982, 94, 64.

[183] A. K. Vainio, H. Paulapuro, Bioresources 2007, 2, 442.

[184] H. Qian, E. S. Greenhalgh, M. S. P. Shaffer, A. Bismarck, J. Mater. Chem. 2010, 20, 4751.

[185] K.-Y. Lee, P. Bharadia, J. J. Blaker, A. Bismarck, Compos. Part A Appl. Sci. Manuf. 2012, 43, 2065.

[186] J. Juntaro, "Environmentally Friendly Hierarchical Composites," in Department of Chemical Engineering, PhD Thesis, Imperial College London, London, 2009, p. PhD/207.

[187] J. Juntaro, M. Pommet, G. Kalinka, A. Mantalaris, M. S. P. Shaffer, A. Bismarck, Adv. Mater. 2008, 20, 3122.

[188] J. Juntaro, M. Pommet, A. Mantalaris, M. Shaffer, A. Bismarck, Compos. Interfaces 2007, 14, 753.

[189] M. Pommet, J. Juntaro, J. Y. Y. Heng, A. Mantalaris, A. F. Lee, K. Wilson, G. Kalinka, M. S. P. Shaffer, A. Bismarck, Biomacromolecules 2008, 9, 1643.

[190] E. S. Greenhalgh, "Failure Analysis and Fractography of Polymer Composites,", Woodhead Publishing Ltd and CRC Press LLC, Cambridge 2009, p 608.

[191] K.-Y. Lee, K. K. C. Ho, K. Schlufter, A. Bismarck, Compos. Sci. Technol. 2012, 72, 1479.

[192] J. Diniz, M. H. Gil, J. Castro, Wood Sci. Technol. 2004, 37, 489. 